\title{
WestVirginiaUniversity
}

THE RESEARCH REPOSITORY @ WVU

Graduate Theses, Dissertations, and Problem Reports

2002

\section{Relationships among spirituality, cognitive processing, and personal control}

Karri Bonner

West Virginia University

Follow this and additional works at: https://researchrepository.wvu.edu/etd

\section{Recommended Citation}

Bonner, Karri, "Relationships among spirituality, cognitive processing, and personal control" (2002). Graduate Theses, Dissertations, and Problem Reports. 782.

https://researchrepository.wvu.edu/etd/782

This Thesis is protected by copyright and/or related rights. It has been brought to you by the The Research Repository @ WVU with permission from the rights-holder(s). You are free to use this Thesis in any way that is permitted by the copyright and related rights legislation that applies to your use. For other uses you must obtain permission from the rights-holder(s) directly, unless additional rights are indicated by a Creative Commons license in the record and/ or on the work itself. This Thesis has been accepted for inclusion in WVU Graduate Theses, Dissertations, and Problem Reports collection by an authorized administrator of The Research Repository @ WVU. For more information, please contact researchrepository@mail.wvu.edu. 
Relationships Among Spirituality, Cognitive Processing, and Personal Control

\author{
Karri Bonner \\ Thesis submitted to the \\ Eberly College of Arts and Sciences \\ at West Virginia University \\ in partial fulfillment of the requirements \\ for the degree of \\ Master of Arts \\ In \\ Psychology \\ Stanley H. Cohen, Ph.D., Chair \\ Barry Edelstein, Ph.D. \\ Julie H. Patrick, Ph.D. \\ Department of Psychology
}

Morgantown, West Virginia
2002

Keywords: Spirituality, Cognitive Processing, Personal Control 


\begin{abstract}
Relationships Among Spirituality, Cognitive Processing, and Personal Control
\end{abstract}

\title{
Karri Bonner
}

The current study was a cross-sectional investigation of how spirituality as a positive life theme might be related to a unique style of cognitive processing. Of secondary interest were the relationships among spirituality and other personal control variables. Using memory recall and recognition tasks, the current study sought to determine whether or not participants would attend more to positive, negative, neutral, or religious words. The results of the current study indicate that (1) older adults are more spiritual than younger adults, (2) higher spirituality is related to higher levels of optimism, (3) spirituality is related to an external locus of control, but only for the unknown forces locus of control, and (4) spirituality neither relates to optimism, nor does it appear to be related to the cognitive bias of optimism. 


\section{ACKNOWLEDGEMENTS}

I would like to thank my committee members, Stan Cohen, Julie Patrick, and Barry Edelstein for all of the helpful insight and advice they provided for me. I am particularly thankful to Stan for not only guiding me through the process of completing my master's thesis, but also for all of the encouragement he offered when I hit a few bumps in the road.

Next I would like to thank the Department of Psychology Alumni, who through the Alumni Fund provided me with funding to conduct this research.

I would also like to thank my family. I could not have made it this far without my parents, David and Becky Bonner, who have provided me with constant support and have always believed in me. In addition, I must give a big "Thank You" to my sister and brother-in-law, Amy and Andrew Riehl, who have always managed to make me smile, even when I didn't feel like it. I could not have done this without any of you. 
Table of Contents

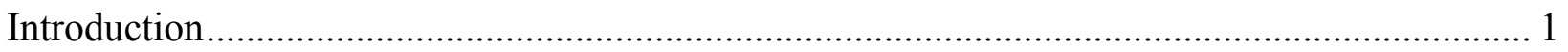

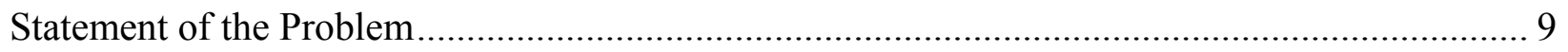

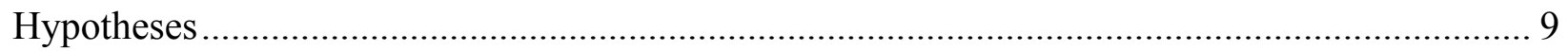

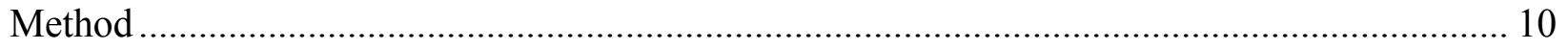

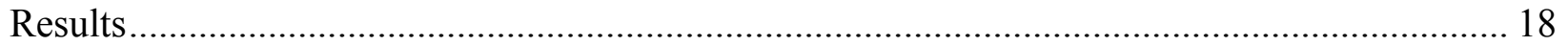

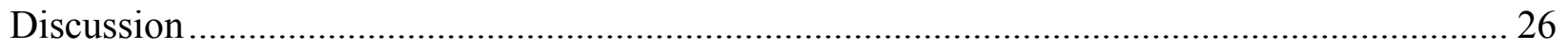

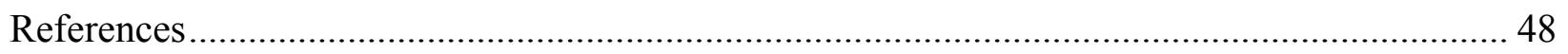

Appendix A: Word Lists Used in Memory Tasks ............................................................... 55

Appendix B: Fetzer Multidimensional Measurement of Religiousness/Spirituality ................... 57

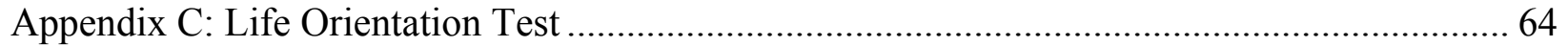

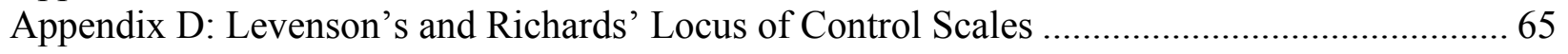

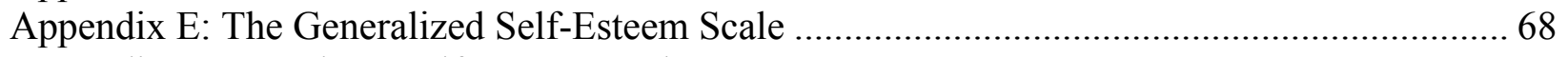

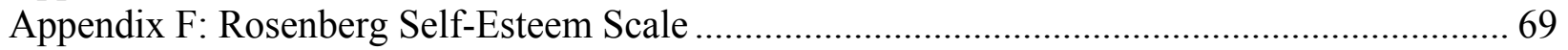




\section{Introduction}

Past research indicates that the experiences of one's life may lead this individual to process information in distinct ways (Kaspi, McNally, \& Amir, 1995). The dominant theme in one's life may be either negative or positive. Negative life themes are defined as the experience of certain negative life events that lead to an overall negative theme in life. Such negative life events would include the experience of being in a severe car accident, developing a chronic illness, or other chronic stressor (Price, Pentecost, \& Voth, 2002). Similarly, positive life themes result from positive life events. Positive life events would include such everyday pleasant activities as having an enjoyable conversation with a friend, dining out, reading, or finding a new friend (Johnson, Crofton, \& Feinstein, 1996; Needles \& Abramson, 1990). In addition, past research has shown that dominant life themes have been associated with personal control variables such as optimism, locus of control, self-efficacy, and self-esteem.

The current study extends from previous literature that examined how negative life themes lead to different styles of cognitive processing and personal control. Negative life themes have been much more widely researched in their relation to these variables, while positive life themes have not received as much attention. Therefore, the goal of this study was to examine how one type of positive life theme, spirituality, may be associated with a particular style of cognitive processing.

The literature review will begin with a general discussion of cognitive processing, a theory of cognitive bias, and then move into how negative life themes affect memory and cognitive processing. Next is a discussion of how positive life themes may influence memory and cognitive processing. This will be followed by the definition of spirituality as a positive life 
theme. Finally, the relation of dominant life themes to the personal control variables of optimism, locus of control, self-efficacy, and self-esteem will be discussed.

\section{Memory and Cognitive Processing}

Contextual influences may partially account for different styles of cognitive processing. Negative life themes, particularly posttraumatic stress disorder and anxiety disorders, have been most widely studied (see Kaspi et al, 1995; McNally, Otto, Horing, \& Deckersbach, 2001, respectively). Life experiences and dominant themes in one's life could influence to what we attend, perceive, and remember. They may influence how one encodes information and how it is recalled. This influence may lie in either the amount of words recalled or the type of words recalled.

Depending on one's theme, certain words can carry a tremendous effect for different people (McNally, Kaspi, Riemann, \& Zeitlin, 1990). In this study, Vietnam veterans with and without posttraumatic stress disorder were given a Stroop test. This task involved the use of positive, neutral, obsessive-compulsive, and PTSD-related words. The participants were instructed to name the color of each word as it was shown to him or her. The individuals with PTSD had a more difficult time identifying the color of stressful words than neutral or positive words (McNally et al., 1990). Kaspi et al. (1995) conducted a similar study and found similar results. In their study, a Stroop task was also used. The participants were presented with four different types of words - positive, negative, neutral, and combat-related words. Kaspi and colleagues found that individuals with PTSD had the most difficult time identifying the colors of combat related words. These words carried personal meaning to individuals with PTSD and may have caused feelings of stress to these individuals. Thus, the stress caused interference when attempting to name the color of the word. 
McNally, Metzger, Lasko, Clancy, \& Pitman (1998) conducted a similar study using participants who were diagnosed with PTSD as a result of sexual abuse. The participants were exposed to positive, neutral or trauma-related words. After each word was presented, they were told to either remember or forget this word. The individuals with PTSD did not display an avoidant encoding style when instructed to forget the trauma related word. These individuals were no more sensitive to these types of words than other types of words. However, the individuals with PTSD showed better recall for trauma-related words than the positive or neutral words. Therefore, the negative life theme of trauma might have led these individuals to attend more to these words than others.

Following this logic, the present study proposed that individuals who have any type of strong themes guiding their lives would pay more attention to those aspects of the environment related to this theme. Specifically, individuals with spirituality as a dominant life theme may attend especially to spiritual aspects of the environment. Also, if those who are highly spiritual have a more optimistic outlook on life, this theme will guide them to attend to more positive aspects of the environment.

\section{Cognitive Bias}

Williamson \& Muller (1999) define cognitive bias as a style of information processing that alters one's judgment, attention, and memory. They theorize that schemas begin to take an active role in cognitive processing. Stimuli will be biased by personal meanings that are associated with a dominant schema. Thus, individuals who have a dominant spiritual schema will process information through this bias.

Recalling the notion that spirituality has been linked to optimism, the investigator is interested in explaining why this phenomenon occurs. Optimism has been shown, at least in one 
study, to be associated with cognitive bias. Schweizer, Beck-Seyffer, \& Schneider (1999) have suggested that optimism is the general expectation that a positive outcome will come about after a problem has been encountered. Optimism has also been shown to be associated with better physical health, better mental health, and a more swift recovery after surgery or illness (Scheier \& Carver, 1987).

Optimism is related to cognitive bias, which is a unique style of information processing. Schweizer et al. (1999) define the cognitive bias of optimism as being a defense mechanism to defend against anxiety. One who uses the cognitive bias will focus on the positive elements of the environment and ignore the negative elements of the environment. Thus, spirituality may also be a component of the cognitive bias. Those who adopt spiritual values in their lives may be more apt to focus positive elements rather than negative elements.

Feelings of personal control

Other variables of interest are optimism and self-esteem. Negative life themes also relate to differences in personal control variables. The experience of negative life themes such as trauma, post-traumatic stress disorder, or abuse have been linked to decreased optimism (Dougall, Hyman, Hayward, McFeely \& Baum, 2001), low levels of self-esteem (Pettit \& Joiner, 2001), and low levels of self-efficacy (Benight et al., 2000). In addition, Mynard, Joseph, and Alexander (2000) have found that those individuals who are at the greatest risk for developing psychological problems due to trauma are those with an external locus of control.

\section{Locus of Control}

Individuals who identify with a higher power often rigidly follow guidelines for living as set by the higher power (Mitchell, 1998). These individuals, Mitchell says, are also likely to resort to excuses such as "the devil made me do it" whenever their behavior does not match the 
so-called guidelines for living that are set by the religion. In this way, these individuals exhibit an external locus of control by insinuating that an external force compelled them to act in such a way. Similar to those individuals who are highly religious, highly spiritual individuals may also exhibit an unknown forces locus of control, as suggested by Richards (1990). This dimension of locus of control is intended to measure feelings of personal control for individuals who are involved with spirituality and cosmic forces (Richards, 1990).

Older adults generally have an internal locus of control and younger adults have an external locus of control (Nunn, 1994). Using Rotter's scale, Nunn found that the older adults in his study were more internally oriented than the younger adults. However, different results were reported by Shaw and Krause (2001). Older age in their study was also associated with lower feelings of control in both African Americans and Caucasians.

Waite, Hawks, \& Gast (1999) reported that self-esteem and locus of control are factors that contribute to spiritual health. Because these are components of spiritual health, one may not be able to conclude that they are the results of living a spiritual lifestyle. This may support a bidirectional relationship. Spirituality contributes to self-esteem and locus of control, while these reinforce spiritual beliefs. Self-Esteem and Self-Efficacy

In college populations, high levels of spirituality and religiosity are related to high selfesteem (Knox, 1998). Similarly, when faced with a crisis, older adults tend to turn to spirituality because of its capability to ward off stress and increase feelings of self-esteem. Religious activities have been shown to counteract feelings of stress (Krause \& Van Tran, 1989). The same study by Krause and Van Tran showed that individuals who reported higher levels of prayer and Bible reading had more intense feelings of personal control over their lives. 
In older populations, spirituality appears to generate feelings of self-esteem. Elderly African American women report that spirituality helps to keep despair at bay, give hope for this life and the next life, and it also gives meaning to their hardship (Black, 1999). However, these findings have not been demonstrated experimentally.

Self-efficacy is defined as "the belief that one can deal effectively with everyday life problems and challenges" (Hoeltje, Zubrick, Silburn, \& Garton, 1996, p. 446). Although the concept of self-efficacy can refer to specific situations, Bandura (1986) recognized that selfefficacy might generalize to other, more global situations. Nosek (2001) found that a relationship exists between spirituality and self-efficacy. This relationship is moderated by the perception that the ability to cope is coming from a divine source. Nosek concludes that through spirituality, individuals find the strength to cope with life's hardships.

All of these personal control variables help people to ward off stress. High levels of these variables are associated with the ability to combat the ill effects of negative life themes. Spirituality, through its association with high levels of these variables, may work to decrease stress and act as a buffer against negative life themes. Therefore, the present study proposed that spirituality would be related to high levels of optimism, self-esteem, and self-efficacy.

\section{Spirituality Defined}

The terms "spirituality" and "religiosity" have sometimes been used interchangeably. Spirituality is defined as "the belief that there is a sacred force that exists in all things" (Potts, as quoted in Mattis, 2000). Religiosity refers to the adherence to specific doctrines, beliefs, and practices of an organized religion (Mattis, 2000). Religious affiliation is not a variable of direct interest in this study, thus spirituality was the construct of interest. 
Spirituality in this study refers to the belief in some type of religion, but not necessarily the practice of religious doctrine or rituals. This definition has been used in other studies (Helminiak, 2001). McFadden (1996) defines spirituality as "the motivational and emotional foundation of the lifelong quest for meaning" (p. 164). This definition implies a more personal experience that is not guided by any religion, specific religious practice, or religious teaching. Spirituality as a Positive Theme in Life

Approximately $95 \%$ of all Americans claim that they have a religious or spiritual affiliation (Plante, Yancey, Sherman, and Guertin, 2000). With spirituality so closely associated with psychological health (Young et al., 2000), the potential benefits of living a spiritual life should be examined in further detail.

Johnson et al. (1996) defined a positive life event as any type of event that is pleasant to engage. There has been much research to support that religiosity and living a spiritual lifestyle bring about pleasant consequences. Religiosity and spirituality are associated with low levels of despair, high levels of optimism, and they serve as a safeguard against negative life themes (Pritt, 1998; Young et al., 2000). This could possibly be the result of the notion that individuals who are highly spiritual attend more to positive aspects of their environment, and attend less to the negative aspects of life. However, no empirical evidence supports this possibility, and there are no existing theories.

Spirituality values have been shown to have positive impacts on one's life. Park, Meyers, and Czar (1988) make the statement that spirituality is an important facet of one's life, as spirituality helps individuals to "easily recognize their unique potentials, gain personal fulfillment and self-worth, and experience higher levels of self-actualization, all of which are essential components of healthy psychological functioning" (p. 550). 
Religious faith is associated with "positive psychological functioning" (Plante et al., 2000). Their study focused on not only religious affiliation but also the strength of religious faith. These researchers found support for the idea that strength of faith is related to many mental health benefits, namely optimism, positive coping, and low levels of anxiety. Developmental implications

Memory. In terms of memory capacity, older adults generally cannot hold as much information in short-term memory storage as younger adults (Smith, 1996). One explanation Smith offers for this is that older adults cannot inhibit thoughts that are irrelevant to the task. Another reason may be that older adults cannot integrate context as well as younger adults. For example, in memory recall tasks, older adults do not perform as well as younger adults (Humphrey \& Kramer, 1999). Even with many hours of training for a particular type of memory task, older adults cannot perform as well on such tasks as younger adults (Baltes \& Finnell, 1992). To further support this idea, other studies have shown that younger adults perform better on working memory tasks than older adults (Wingfield, Stine, Lahar, \& Aberdeen, 1988; Dobbs \& Rule, 1989; Laumann, 1999).

Spirituality. In longitudinal studies, older adults tend to be highly religious and highly spiritual (Wink \& Dillon, 2002). Furthermore, Ita (1995) also found that older adults report higher levels of spirituality than younger adults and also that older adults derive more comfort through spirituality. In Ita's research, having higher levels of spirituality helped to reduce feelings of anxiety over death. Although it has not been widely studied, McFadden (1996) states that some researchers believe that older age brings about thought processes that are characterized by "wisdom, unitative states of consciousness, transcendence, and awareness of multiple 
realities" (p. 170). This leads researchers to conclude that adults may become increasingly spiritual as they age.

\section{Statement of the Problem}

The present study proposed that a cognitive bias would be present for individuals who are highly spiritual. Most spiritual people believe in some type of afterlife, and feel anxious when they expect they may not reach a desired end state. To avoid punishment (or anxiety), these individuals concentrate on positive aspects of life and ignore the negative aspects of life, therefore expressing a cognitive bias. This process was studied through the use of memory recall and memory recognition tasks. These tasks involved the use of four different types of wordspositive, negative, neutral, and religious. The intention was to examine what types of words are recalled the most or recognized the easiest.

Spirituality appears to have long reaching impacts on one's life, and its positive effects should be explored in more detail. Spirituality is associated with a positive attitude, high selfesteem, high self-efficacy, and optimism. Optimism has been associated with different types of cognitive processing styles, such as the cognitive bias of optimism. Taken a step further, the present study reasoned that if spirituality is so strongly linked to optimism, it may also be associated with a cognitive bias; perhaps a cognitive bias of spirituality.

The hypotheses of the study are as follows:

1. There will be an interaction between age, spirituality, and type of word recalled. Older adults, because they are highly spiritual, will display a cognitive bias towards positive elements (i.e., the positive words on the memory tasks). However, regardless of age, anyone with high levels of spirituality will be more apt to remember the most positive words because of the cognitive bias. 
2. Older adults will be more religious (Taylor, 1999) and spiritual (Wink \& Dillon, 2002)than will younger adults, which is consistent with the literature.

3. Individuals who score high on the spirituality assessment will also score in the high range on the optimism assessment. Literature has consistently supported this hypothesis (Schutte \& Hosch, 1996).

4. Regardless of age, high levels of spirituality will be associated with an external locus of control, high self-esteem, and high self-efficacy.

\section{Method}

\section{Participants}

A comparison between younger adults and older adults was used because previous research has shown that older adults are generally more spiritual than younger adults. Of interest was how the different age groups were affected by spirituality. Overall, 80 individuals (31 males, 46 females; three individuals did not report gender) participated in the current study. There were 40 participants in the younger adult sample, 22 males and 18 females; with a mean age of 19.0 years (range $=18$ to 25$)$. Most of the younger adults reported an income of less than $\$ 10,000$ per year and the average years of education reported was 13.4 (range $=12-17)$. Most participants were Caucaisan (98\%) and one participant was African American. Twelve participants reported their religious affiliation as Catholic, nine indicated Other, eight reported being Baptist, eight reported being Protestant, and 3 did not report religious affiliation. The mean age for the older adult sample was 72.6 years (range $=59-90)$. Most participants reported an average yearly income of $\$ 10,000$ to $\$ 20,000$ per year. Mean number of years of education was 12.5 years (range $=4-23$ ). Consistent with the demographics of the region, most participants 
were Caucasian (88\%) and four were African American (10\%). Four participants did not indicate race $(2 \%)$. Studies have shown that there are racial differences in level of spirituality (Taylor, 1999; Black, 1999), so a homogeneous group was advantageous in this study. Religious affiliation was: 21 of the participants reported Protestant, 12 reported Catholic, 5 reported Other, and 2 reported Baptist.

The participants in the younger adult sample were all students enrolled in introductory psychology courses. As an incentive for participation, they were offered extra credit points based on the number of hours of participation. Sampling from undergraduates taking psychology classes allowed for a high degree of variability in spirituality.

The participants in the older adult sample were obtained through flyers and visits to local senior centers and retirement complexes. The investigator either called the directors of the senior centers on the telephone or visited the directors in person. Flyers were posted on bulletin boards at the senior centers, upon approval by the director. As an incentive for participation, the participant's name was placed in a drawing for a 50-dollar gift certificate to a local shopping center.

\section{Measures}

The following constructs were measured in this study: spirituality, memory, optimism, locus of control, self-efficacy, and self-esteem. A short demographic questionnaire was also administered. The demographic questionnaire included age, race, hometown, income, religious affiliation, education, and length of residence in West Virginia. There were also two questions to measure perceived optimism/task self-efficacy. These two questions asked participants to rate how well they thought they would perform on the memory tasks. 
Spirituality. To measure spirituality, the Fetzer Multidimensional Measurement of Religiousness/ Spirituality was used (see Appendix B). This measure has an overall reliability score of approximately $\alpha=.73$ (Fetzer Organization, http://www.fetzer.org). The reliability coefficients for the subscales are as follows: For private religious activities, $\alpha=.72$, for public religious activities, $\alpha=.82$, and for daily spiritual experiences, $\alpha=.64$. This scale measures spirituality, support, and coping in a short 38-item form. Based on data from the results of the 1998 General Social Survey, the Fetzer Multidimensional Measurement of Religiousness and Spirituality is a valid instrument that researchers should continue to use (Idler, 1999, as cited in Fetzer, 1999).

Optimism. The Life Orientation Test (LOT) (Scheier \& Carver, 1987) was used to measure optimism (see Appendix C). This 8-item questionnaire uses a 5-point Likert type scale ranging from Strongly Disagree to Strongly Agree, and measures one's outlook on life (Scheier \& Carver, 1987). With a Cronbach's alpha of .76, this test has reasonable internal reliability (Scheier \& Carver, 1987). It also has good test-retest reliability $(\mathrm{r}=.79)$. The LOT also correlates moderately with "self-esteem, depression, hopelessness, alienation, and perceived stress," (Scheier \& Carver, 1987). Scheier, Carver, and Bridges (1994) report that the scale has good discriminant validity. In their study, the LOT correlated only moderately with such measures as neuroticism, self-mastery, trait anxiety, and self-esteem. The shared variance among these factors was also reported as moderate, indicating that optimism is distinct from these other variables. Although a revised version of the scale exists (Scheier, Carver, \& Bridges, 1994), it was not available for use at the time of the current study.

Cognitive Processing. The memory task included a recall component and a recognition component. In both conditions, the participants were visually presented with two word lists, 
each containing 40 words. These lists included 10 of each of the following types of words: neutral words, positive words, negative words, and religious words. The words were obtained through lists compiled by Thorndike and Lorge (1944). The words on these lists were rated for difficulty and exposure. The words used in the tasks were drawn from lists that were matched on levels of difficulty and exposure. Although the lists may seem outdated, this had its advantage; words associated with technology and/or modern conveniences were not on the lists, making it more fair for the older adults in the study. However, this is not to say that the words were outdated or terribly unfamiliar to the young adults either. All of the words were appropriate for someone with at least a $10^{\text {th }}$ grade education and were among the most frequently used words in the English language (Thorndike \& Lorge, 1944).

The word lists were obtained from a study conducted by Rinck, Glowalla, \& Schneider, (1992) and also from Cloitre \& Liebowitz (1991). These word lists (see Appendix A) were used in cognitive testing for mood congruent learning and memory bias, respectively. The word lists were normed by having them rated by Introduction to Psychology students. Each word was given a rating between -3 for "very unpleasant" and +3 for "very pleasant" (Rinck et al., 1992). The same procedures were used in Cloitre \& Liebowitz (1991) with the positive words having a mean rating of +1.63 , the negative words having a mean rating of -1.65 , and the neutral words having a mean rating of +0.25 . Filler words, used in the recognition task, were obtained from the Teacher's Word Book of 30,000 Words (Thorndike \& Lorge, 1944). These filler words were also matched for affect. Pilot data using younger and older adults indicated that there was a high percentage of agreement over the affective connotation of each word. In addition, these filler words were selected from the word lists of the most frequently occurring words in the English language. 
Locus of Control. Locus of control was measured using the Multidimensional Locus of Control Assessment (see Appendix D). This instrument is a collection of 24 statements to which the participant responds in a Likert type format (Levenson, 1973). These 24 statements are divided into three 8-item subscales. First is a scale to measure internal locus of control. This 8item subscale has an extremely low test-retest correlation of .08, as reported by Levenson (1973). However, although this low correlation was obtained, the difference between the score at time one and the scores at time two were not significantly different from one another. Next, external locus of control is measured by dividing it into two subscales, powerful others and chance (Levenson, 1973). These subscales have satisfactory test-retest reliability coefficients of .74 and .78 , respectively.

In addition to Levenson's measure was the unknown forces subscale, which is used to measure and understand locus of control in those individuals who are involved in spirituality (Richards, 1990). Richards reports a reliability coefficient of $\alpha=.56$ for the unknown forces subscale. This subscale has been shown by Richards to be distinct from the 3 other locus of control scales, suggesting that the unknown forces scale measures a separate realm of control. The 4 subscales of the Locus of Control scale also have satisfactory discriminant validity. Richards indicates that the internal subscale is not correlated with the other three external subscales (chance, powerful others, or unknown forces). The four subscales are clearly distinct from one another; factor analyses conducted by Levenson (1973) and by Richards have yielded four distinct factors with virtually no item overlap.

Self-Efficacy. Self-efficacy was measured using the General Self-Efficacy Scale (see Appendix E). This instrument is a brief ten-item questionnaire that examines overall confidence in one's ability to cope in stressful situations (Schwarzer, Babler, Kwiatek, Schroder, \& Zhang, 
1997). This measure has internal consistencies that vary between alpha $=.75$ and .90 . Higher scores on the measure indicate higher self-efficacy. Lower scores indicate lower self-efficacy. The scale has good convergent and discriminant validity: Self-esteem and optimism correlate positively with the scale while depression and anxiety are negatively correlated with the scale (Schwarzer et al., 1997).

Self-Esteem. Finally, self-esteem was measured using Rosenberg's Self-Esteem Scale (see Appendix F). A low score on this measure indicates low self-esteem and a high score indicates high self-esteem. This instrument has been widely used since the 1960's and displays good test-retest reliability. A test-retest correlation of .85 was obtained over a two-week time span (Robinson and Shaver, 1980). (See Table 1 for a list of the properties of the measures). The scale has satisfactory convergent and predictive validity. Robinson and Shaver (1980) report that it correlates with Coopersmith's Self-esteem Inventory, $r=.60$, showing convergent validity. The scale also has good predictive validity, as it is related to less shyness, less depression, and higher levels of assertiveness (Rosenberg, 1965, as cited in Robinson \& Shaver, 1980).

Design

This study utilized a cross-sectional design. The independent variables in the study were age and spirituality. Younger adults were compared to older adults. This allowed for the investigation of differences between the younger adult sample and the older adult sample, which was one of the goals of this study. Although this did not enable any assumptions to be made concerning the development of spirituality over the life span, this study was able to examine these age-related differences. Groups were compared based on age (younger vs. older adults) and spirituality (high vs. low), using correlational analyses and analysis of variance. 
High levels of spirituality were compared to low levels of spirituality. These were defined by the results obtained on the Fetzer Multidimensional Measurement of Religiousness/Spirituality. Using a median split, a high score on this measure indicated high spirituality while a low score indicated low levels of spirituality. Dependent variables were cognitive processing and the personal control variables. Cognitive processing was measured through the use of the recall and recognition memory tasks. The personal control measures were operationalized through the scores obtained on the different measures.

\section{Procedures}

Because this study utilized self-report questionnaires and two short memory tasks, presenting the information to large groups was not problematic. A large classroom was used to assess approximately 10-15 younger adults at once, depending on the availability of research assistants. When assessing older adults, large meeting rooms were used. These meeting rooms and the group sizes were comparable to the classrooms used with the younger adults.

The session lasted approximately one hour, with the younger adults finishing much more quickly than the older adults. First, the participants were told what the study involved and they were asked to read and sign a consent and information form. After the participants returned the consent form, the memory tasks were begun. Upon completion of the two memory tasks, the participants filled out the remaining measures.

The participants were then given the memory recall task. Forty words, 10 positive, 10 negative, 10 neutral, and 10 religious were presented to the participants on a television screen from a VCR videotape that had been previously recorded. The letters were centered in the middle of the television screen (approximately 3 inches high, depending on the television set) in 
all capital letters, with sharp color contrasts for easier readability. The background of the slide was white, and the word was colored in black.

While seated at a desk or around a table, the participant had the following materials: one sheet of blank paper, one pencil or pen, and a list of words for the memory recognition task (see appendix) encased in a folder. The participants were then presented with the positive, negative, neutral, and religious words at a rate of two seconds each. The words were arranged in such an order that no more than two of the same type of word were presented consecutively.

After all of the words had been presented, participants were asked to write down as many words as they could remember. Pilot testing indicated that three minutes was adequate time to complete the tasks for both age groups. Therefore, participants were given a maximum of three minutes to do this. After three minutes, they were instructed to put the paper aside and to not write anything else on it.

Next, participants were shown a second list of words for the recognition task. These words were completely new. The list contained words that were similar to the previous list, insofar as they shared the same format of the positive, negative, neutral and religious connotations. This list was presented in the same manner as the previous list.

Participants were asked to remove the first sheet of paper from their folders and place it face down on their desks. This paper contained 40 words from the second list as well as 40 new "filler" words that had not been seen previously. These filler words were not presented visually, but they were used as distracters from the words that were presented on the second list. After the second list of words had been presented, they were then instructed to turn the paper face-up and circle any word that they remember seeing from the second list of words. To avoid the possible 
confound of proactive interference, words appearing on the recall task list did not appear on the recognition task list.

A maximum of five minutes was allowed to complete this task, the same time allotment used by Cloitre \& Liebowitz (1991) in their memory task. However, most participants completed this task in less than three minutes. Upon completion, the participants were instructed to open their folders and begin working on the remaining testing materials. The participants were permitted to take as much time as needed to complete these measures. These tasks were counterbalanced so that half of the participants were administered the recall task first while the other half received the recognition task first. After the participants had completed the study, they were debriefed and asked to not tell anyone the purpose of the study.

\section{Results}

Hypothesis 1 was not supported. Hypothesis 1 proposed a three-way interaction (age $\mathrm{x}$ type $x$ spirituality) in which older adults would recall more of the positive words on the task than younger adults, due to their higher overall spirituality. A repeated measures analysis of variance was conducted to test a three-way interaction among spirituality, age, and type of word remembered. This three-way interaction was not significant. Throughout all of the tasks, there were no significant main effects for high or low spirituality; it was unrelated to differential recall or recognition of any word type.

Memory Recall Task

First, there were main effects present for age, $\mathrm{F}(1,74)=8.30, p<.005$, and for type of word recalled, $\mathrm{F}(3,222)=30.28, p<.001$ (see Table 6). Younger adults recalled an average of 11.3 words $(\mathrm{SD}=3.34)$, while older adults recalled an average of 8.3 words $(\mathrm{SD}=6.1)$. For type of word recalled, religious words were recalled the most $($ Mean $=3.8, \mathrm{SD}=2.3$ ), positive words 
were recalled the second most $($ Mean $=2.4, \mathrm{SD}=1.5)$, the third most recalled word type was negative $($ Mean $=2.0, \mathrm{SD}=1.8)$, followed by neutral $(\mathrm{Mean}=1.9, \mathrm{SD}=1.5)$. There was a significant interaction for the age $\mathrm{x}$ type effect, $\mathrm{F}(3,222)=5.79, p<.001$ (see Figure 1 ). Younger adults recalled more positive words $($ Mean $=2.7, \mathrm{SD}=1.2)$, than older adults $($ Mean $=$ 2.1, Standard Error $=1.8)$, but this effect was not significant, $\mathrm{t}(76)=1.72, n s$. Younger adults also recalled more negative words than older adults $\left(\mathrm{Mean}_{\text {young }}=2.1, \mathrm{SD}_{\text {young }}=.3\right)$ and $\left(\mathrm{Mean}_{\text {older }}=1.9, \mathrm{SD}_{\mathrm{older}}=.27\right)$. The difference between these means was not significant (see Table 4). Younger adults also remembered more of the neutral words (Mean $=2.3, \mathrm{SD}=1.5$ ) than the older adults $($ Mean $=1.6, \mathrm{SD}=1.6)$. Using Fisher's LSD test, the difference between these means was significant, $\mathrm{t}(76)=2.22, p<.05$. Finally, younger adults recalled many more religious words $(\mathrm{Mean}=4.5, \mathrm{SD}=2.0)$ than the older adults did $($ Mean $=2.8, \mathrm{SD}=2.0)$. The difference between these means was significant, $\mathrm{t}(76)=6.45, p<.001$.

\section{Memory Recognition Task}

Significant main effects for age, $\mathrm{F}(1,74)=19.03, p<.001$, and type of word, $\mathrm{F}(1,222)$ $=7.23, p<.001$ (see Table 7), were also found in the memory recognition task. Younger adults recognized a mean of 29.4 words $(\mathrm{SD}=8.25)$ while older adults only recognized a mean of 21.9 words $(\mathrm{SD}=9.62)$. Negative words were recognized the most $($ Mean $=7.1, \mathrm{SD}=2.4)$, followed by religious $($ Mean $=7.0, \mathrm{SD}=2.3)$, positive $(\mathrm{Mean}=6.4, \mathrm{SD}=2.7)$, and finally neutral $($ Mean $=6.1, \mathrm{SD}=3.0$ ). A significant age $\mathrm{x}$ type effect was found also for the memory recognition task, $\mathrm{F}(3,222)=7.50, p<.001$ (see Figure 2). Younger adults recognized more positive words $($ Mean $=7.7, \mathrm{SD}=2.0)$ than older adults $($ Mean $=5.0, \mathrm{SD}=2.7)$. Using Fisher's LSD test, the difference between these means was significant, $\mathrm{t}(76)=6.05, p<.001$. Younger adults recognized more of the negative words $($ Mean $=7.5, \mathrm{SD}=1.8)$ than older adults. This difference 
was not significant (see Table 5). Younger adults recognized more of the neutral words (Mean = $7.5, \mathrm{SD}=2.3)$ than the older adults $($ Mean $=4.8, \mathrm{SD}=2.8)$. This difference was significant using Fisher's LSD test, $\mathrm{t}(76)=6.16, p<.001$. Lastly, younger adults also recognized more of the religious words $($ Mean $=7.9, \mathrm{SD}=1.4)$ than the older adults $($ Mean $=6.2, \mathrm{SD}=2.7)$. The difference between these means using Fisher's LSD test was significant, $\mathrm{t}(76)=3.82, p<.001$. The largest difference between the groups was for the positive words, with younger adults recalling an average of 2.7 more words than older adults.

\section{Memory Recall Task - Percentages}

When total memory was controlled using percentage of total words recalled in each word type, there was a main effect only for type of word recalled in the memory recall task, F $(3,219)$ $=14.4, p<.001$ (see Table 8). Religious words were recalled the most, representing a mean of $36 \%$ of all the words correctly recalled $(\mathrm{SD}=16.0)$. Positive words were the second most recalled, representing a mean of $25 \%$ of all of the words correctly recalled $(\mathrm{SD}=18.0)$. Next were the neutral words, representing a mean of $19.7 \%$ of all of the words correctly recalled (SD $=14.0$ ). Finally, negative words were the least recalled, representing $19.3 \%$ of all of the words correctly recalled $(\mathrm{SD}=11.0)$. The interaction between age and type was not significant (see Figure 3), nor was the three-way interaction between age, word type, and spirituality.

\section{Memory Recognition Task-Percentages}

When total memory was controlled using percentages of each word type in the recognition task, there was a main effect for word type, $\mathrm{F}(3,222)=6.5, p<.001$ (see Table 9). Religious words were the most recognized, representing approximately $28.5 \%(\mathrm{SD}=16.2)$ of the words correctly circled on the participant's recognition worksheet. This was followed by negative words $($ Mean $=28.3 \%, \mathrm{SD}=10.7)$, positive words $($ Mean $=24.4 \%, \mathrm{SD}=17.6)$, and 
neutral words $(\mathrm{Mean}=22.7 \%, \mathrm{SD}=11.2)$. There was also a significant age $\mathrm{x}$ type interaction $\mathrm{F}$ $(3,222)=5.78, p<.001$ (see Figure 4). Younger adults recognized more positive words on the list $($ Mean $=28 \%, \mathrm{SD}=22.8)$ than older adults $($ Mean $=21 \%, \mathrm{SD}=8.8)$. The difference between these means was significant, Fisher's LSD t $(76)=3.20, p<.001$. Younger adults recognized fewer of the negative words $($ Mean $=26 \%, \mathrm{SD}=12.6)$ than the older adults $($ Mean $=$ $31 \%, \mathrm{SD}=8.0)$. The difference between these two means was significant, Fisher's LSD t $(76)=$ $-2.25, p<.05$. Younger adults recalled more neutral words $($ Mean $=25 \%, \mathrm{SD}=11.0)$ than older adults $($ Mean $=20 \%, \mathrm{SD}=11.1)$. The difference between the groups was significant, $\mathrm{t}(76)=$ $2.39, p<.05$. Finally, younger adults recognized slightly more religious words $($ Mean $=28.5 \%$, $\mathrm{SD}=20.2)$ than older adults $($ Mean $=28.3 \%, \mathrm{SD}=11.2)$. This difference was not significant. The largest difference between the groups was for the positive words. Out of all of the correctly recognized words, younger adults had an average of 7 percent more positive words circled on the recognition worksheet than did the older adults.

Hypothesis 2 was supported. This hypothesis stated that older adults would be more spiritual than younger adults (see Table 2). A 2 x 2 analysis of variance was conducted on the variables for age (older vs. younger) and spirituality (high or low). Older adults did indicate higher overall spirituality than younger adults, $\mathrm{F}(1,80)=14.3, p<.01$. The mean score on the Fetzer scale for the younger adults was $100.2(\mathrm{SD}=20.69)$ and the mean score for older adults was $117.8(\mathrm{SD}=21.06)$.

Hypothesis 3 was also supported. Hypothesis 3 stated that individuals who were highly spiritual would also be highly optimistic. Correlational analysis (see Table 3) was performed between the Fetzer Scale and the Life Orientation Test. High levels of spirituality were associated with high levels of optimism, $\mathrm{r}=.38, p<.001$. 
Hypothesis 4 was partially supported. Hypothesis 4 stated that high spirituality would be related to an external locus of control, high self-esteem, and high self-efficacy. Correlational analyses were conducted among the Fetzer scale, the subscales of the Multidimensional Locus of Control Scale, the Self-Efficacy Scale, and the Rosenberg Self-Esteem Scale. High spirituality was related to only one aspect of external locus of control, specifically the unknown forces locus of control, $\mathrm{r}=.50, p<.01$. Spirituality was not significantly related to internal locus of control, chance locus of control, powerful others locus of control, self-esteem, or self-efficacy. Most of the correlations among these variables approached zero (see Table 3).

Although the main focus of the current study was spirituality, the instrument used to measure spirituality can be can be decomposed into several subscales, some regarding religiosity while others regard spirituality. The subscales include daily spiritual experiences, values and beliefs, forgiveness, private religious experiences, religious and spiritual coping, religious support, and organizational religion. These subscales were analyzed in their relation to the memory tasks and the personal control variables.

\section{Subscales of the Fetzer}

These subscales did not significantly correlate with memory for any specific type of word, regardless of whether the subscales were correlated with recall or recognition. However, all subscales were related to the unknown forces subscale of the locus of control scale. Unknown forces was highly related to daily religious experiences, $\mathrm{r}=.48, \mathrm{p}<.01$; values and beliefs, $\mathrm{r}=.49, \mathrm{p}<.01$; forgiveness, $\mathrm{r}=-.48, \mathrm{p}<.01$; private religious experiences, $\mathrm{r}=.35, \mathrm{p}<$ .01 ; religious and spiritual coping, $\mathrm{r}=.35, \mathrm{p}<.01$; religious support, $\mathrm{r}=.44, \mathrm{p}<.01$; and organizational religion, $\mathrm{r}=.34, \mathrm{p}<.01$. 
In addition, the Life Orientation Test correlated significantly with the following subscales of the Fetzer: daily spiritual experiences $(\mathrm{r}=.32, \mathrm{p}<.01)$, private religious experiences $(\mathrm{r}=.32$, $\mathrm{p}<.01)$, religious and spiritual coping $(\mathrm{r}=.35, \mathrm{p}<.01)$, religious support $(\mathrm{r}=.44, \mathrm{p}<.01)$ and organizational religiousness $(\mathrm{r}=.27, \mathrm{p}<.05)$. Values and beliefs was related to self-efficacy, $\mathrm{r}=$ $-.26, \mathrm{p}<.05$

\section{Attendance at religious services}

Using one question from the Fetzer scale concerning attendance at religious services, a comparison was made (using a median split at 3.5) between participants who reported regular attendance at services and those who did not. There were significant differences between these groups on the overall Fetzer scale, $F(1,73)=65.25, \mathrm{p}<.0001$. Those who did not report frequent attendance at religious services had a lower mean score on the Fetzer scale $(\mathrm{M}=91.1$, $\mathrm{SD}=19.5)$ than those who did report frequent attendance at religious services $(\mathrm{M}=123.4, \mathrm{SD}=$ 14.8). There were significant differences between these groups on the Life Orientation Test, $F$ $(1,73)=9.669, \mathrm{p}<.003$. Those who did not report frequent attendance at religious services had a lower mean score on the Life Orientation Test $(\mathrm{M}=17.5, \mathrm{SD}=6.3)$ than those who did report frequent attendance at religious services $(\mathrm{M}=21.38, \mathrm{SD}=4.3)$. Finally, there were significant differences between these groups on the unknown forces subscale, $F(1,73)=4.760, p<.032$. On the unknown forces subscale, those who did not report frequent attendance at religious services had a lower mean score on this measure $(\mathrm{M}=24.281, \mathrm{SD}=7.5)$ than those who did report frequent attendance at religious services $(\mathrm{M}=27.48, \mathrm{SD}=5.0)$.

\section{Self-report of religiosity or spirituality}

Religiosity. One item on the Fetzer scale concerned an overall evaluation of how religious one is. Using a median split at 2.7 on this item, comparisons were made between those 
who reported themselves to be religious or not. There were significant differences between these groups on the Fetzer, $F(1,79)=33.76, \mathrm{p}<.0001$. Those who reported how religiosity had a lower mean score on the Fetzer $(\mathrm{M}=92.6, \mathrm{SD}=22.6)$ than those who reported high religiosity $(\mathrm{M}=118.3, \mathrm{SD}=16.6)$. There were significant differences between these groups on the Life Orientation Test, $F(1,76)=6.18, p<.015$. Those who reported how religiosity had a lower mean score on the Life Orientation Test $(\mathrm{M}=17.4, \mathrm{SD}=5.8)$ than those who reported high religiosity $(M=20.6, S D=5.0)$. There were significant differences between these groups on the unknown forces subscale, $\mathrm{F}(1,76)=4.828, \mathrm{p}<.031$. Those who reported low religiosity had a lower mean score on the unknown forces subscale $(\mathrm{M}=24.0, \mathrm{SD}=7.9)$ than those who reported high religiosity $(\mathrm{M}=27.3, \mathrm{SD}=5.2)$.

Spirituality. One item on the Fetzer scale concerned an overall evaluation of how spiritual one is. Using a median split at 2.8 on this item, comparisons were made between those who considered themselves to be spiritual or not spiritual. There were significant differences between these groups on the Fetzer, $F(1,73)=51.20, \mathrm{p}<.0001$. Those who reported low spirituality had a lower mean score on the Fetzer $(\mathrm{M}=83.5, \mathrm{SD}=14.7)$ than those who reported high spirituality $(\mathrm{M}=117.3, \mathrm{SD}=18.7)$. There were significant differences between these groups on the Life Orientation Test, $\mathrm{F}(1,73)=11.827, \mathrm{p}<.001$. Those who reported low spirituality had a lower mean score on the Life Orientation Test $(\mathrm{M}=16.0, \mathrm{SD}=6.0)$ than those who reported high spirituality $(M=20.8, S D=4.9)$. There were significant differences between these groups on the internal locus of control subscale, $\mathrm{F}(1,73)=4.16, \mathrm{p}<.045$. Those who reported low spirituality had a higher mean score on the internal subscale $(\mathrm{M}=36.21, \mathrm{SD}=6.0)$ than those who reported high spirituality $(\mathrm{M}=33.23, \mathrm{SD}=5.3)$. There were significant differences between these groups on the unknown forces subscale, $F(1,73)=5.09, p<.027$. Those who 
reported low spirituality had a lower mean score on the unknown forces subscale $(\mathrm{M}=23.2$, SD $=8.1)$ than those who reported high spirituality $(\mathrm{M}=26.9, \mathrm{SD}=5.5)$.

\section{Demographic Analyses}

There were no significant differences among individuals of different races or religious affiliations on overall spirituality, optimism, or any of the personal control variables. There were significant differences among individuals of different religious affiliations on the types of word recalled or recognized. There was a significant main effect for religious affiliation on percent of positive words recalled, $\mathrm{F}(1,77)=3.9, p<.023$. The Protestant group recalled more positive words $(M=30 \%, S D=21.1)$ than the Catholic group $(M=20 \%, S D=13.8)$. Post hoc LSD tests revealed that this difference was significant, $\mathrm{t}(78)=9.884, \mathrm{p}<.02$. There was also a significant main effect for religious affiliation on percentage of religious words recalled, F (2, $78)=3.2, p<.04$. The Other group recalled more religious words $(\mathrm{M}=44 \%, \mathrm{SD}=16.5)$ than the Protestant group $(M=32, S D=9.0)$. Post hoc LSD tests revealed that this difference was significant, $\mathrm{t}(78)=.821, p<.036$.

A significant main effect for race was found for percent of positive words recalled, F (1, $75)=8.36, p<.05$. Post hoc tests revealed that the African American group recalled significantly more of the positive words $(\mathrm{M}=60 \%, \mathrm{SD}=56.5)$ than the Caucasian group $(\mathrm{M}=$ $24 \%, \mathrm{SD}=15.9)$. There was a main effect for race on percent of neutral words recognized, $\mathrm{F}(1$, $75)=6.80, p<.01$. Post hoc tests revealed that the African American group recognized a lower percentage of the neutral words $(\mathrm{M}=3 \%, \mathrm{SD}=4.4)$ than the Caucasian group $(\mathrm{M}=24 \%, \mathrm{SD}=$ 11.1). There was a significant main effect for race on total number of neutral words recognized, $\mathrm{F}(1,75)=7.80, p<.006$. Post hoc tests revealed that the African American group recognized fewer total neutral words $(\mathrm{M}=.5 \%, \mathrm{SD}=.7)$ than the Caucasian group $(\mathrm{M}=6 \%, \mathrm{SD}=2.8)$. 


\section{Discussion}

Three of the hypotheses in the current study were supported. Two of the findings were consistent with past research. First, older adults did report high levels of spirituality in comparison to younger adults. This effect has been seen consistently throughout past literature (Ita, 1995), and the current study was no exception. Second, a strong relationship between spirituality and optimism was found, which is consistent with studies by Plante et al. (2000) and Slavik \& Croake (2001). Therefore, the current study adds to the literature by strongly supporting these links.

The fourth hypothesis was partially supported. This hypothesis stated that high spirituality would be related to an external locus of control, high self-esteem, and high selfefficacy. Spirituality was related to an external locus of control, but only the unknown forces locus of control. This relationship between the two was expected, as the scale was constructed to measure locus of control for "spiritual seekers" (Richards, 1990). Thus, the current study lends support to the validity and utility of Richards' Locus of Control Scale. The unknown forces locus of control also correlated significantly with all of the subscales of the Fetzer scale. Regardless of whether these scales were associated with religiosity, spirituality, or both, all of them were highly related to the unknown forces locus of control.

However, spirituality was not related to an internal locus of control. Highly spiritual individuals may be more prone to believing in a higher power that controls their fate. In this regard, it makes intuitive sense that one who is highly spiritual would be more likely to display an external locus of control. A recent study by Shaw and Krause (2001) supports this; individuals with higher levels of spirituality reported less personal control. 
Interestingly, however, spirituality did not relate to powerful others locus of control or chance locus of control. Perhaps participants who were highly spiritual regard their personal control as not a function of fate, good luck, or bad luck. Rather spiritual individuals in the present study do believe that there are unknown forces in the universe. In addition, these results indicate that highly spiritual individuals do not believe that any living person has complete control over their lives. More accurately, highly spiritual individuals believe in that there are unknown forces in the universe that control their destiny.

Spirituality, as measured by the Fetzer scale, was not related to self-efficacy or selfesteem. This finding is inconsistent with past research, which has demonstrated that highly spiritual or religious individuals have high levels of self-esteem and self-efficacy (i.e., Black, 1999; Plante et al., 2000). The finding in this study that spirituality is unrelated to self-efficacy is consistent with the finding that highly spiritual individuals have a more external locus of control. Self-efficacy is defined as the ability to cope with stressful situations or the ability to handle stressful events (Schwarzer et al., 1997). Therefore, it is plausible that one who has an external orientation towards personal control would also report lower levels of self-efficacy.

However, one subscale of the Fetzer subscale did correlate with self-efficacy: the values and beliefs subscale, which taps into whether or not one believes that God is watching over them or whether or not individuals feel personally responsible for "reducing pain and suffering in the world." There was a negative relationship between these two variables, but because the two questions are quite different, conclusions cannot easily be drawn; a high score on this subscale indicated both a strong belief that God is watching over and strong feelings of personal responsibility. Therefore, one explanation for this finding is that individuals who have high spiritual values and beliefs may have less free will. Although these individuals may have 
feelings of personal responsibility, they may still feel that their actions are not of their own free will and that God is working through them.

Self-esteem, as unrelated to spirituality, has not been shown consistently in the past literature. When this effect was shown, usually the participants in the study were African American (Taylor, 1999) or with individuals who attend church services regularly. The current study included an overwhelmingly large proportion of Caucasians, which may account for why this relationship was not found. An alternate explanation might be that while these individuals reported high levels of spirituality, they did not attend regular church services. However, the current study indicated a positive relationship between self-report of spirituality and frequency of attending church services, $r=.45, p<.01$. A positive relationship was also found between selfreport of overall religiosity and frequency of attending church services, $r=.42, p<.01$. Therefore, the critical distinction between spirituality and religiosity did not appear to account for the differential relationship each has with self-esteem.

The expected three-way interaction among age, spirituality, and type of word remembered was not significant, but there were significant interactions between age and type of word remembered for several analyses: raw number of words recalled, raw number of words recognized, and percentage of words recognized. In the memory recall task (using raw numbers), younger adults correctly recalled more words, which is in accord with general theories of cognition. In addition, younger adults recalled more of each type of word than older adults, which was expected. Unexpectedly, the younger adults recalled the greatest number of positive words on the list. Older adults, who were much more spiritual than the younger adults, recalled very few of the positive words on the task. However, the absolute difference between the groups was not large. This contradicts the premise of the current study, which held that individuals that 
are highly spiritual would filter out the negative words and focus on the positive words because of cognitive bias.

The results, however, may not be in direct contradiction to the cognitive bias theory, as older adults recalled fewer negative words than did younger adults. This difference, however, was not statistically significant. Yet, there was a trend toward older adults recalling fewer negative words, especially in the highly spiritual group. Older, highly spiritual participants did recall the fewest negative words; although they may have "filtered" out the negatives, this did not lead the participants to focus exclusively on the positive. While this effect was not significant, the results do indicate that cognitive bias may be present, but only weakly influenced participants' cognitive processing in these particular tasks. There were significant differences between the two age groups for recall of neutral words and religious words, with younger adults recalling more of each type of word. The increased recall of neutral words by the younger adults was likely a function of the better overall memory performance shown by this group.

For the religious words, younger adults may have found these words to be more salient due to their unfamiliarity. Although it is counter to the rationale of the study, it is possible that the spiritual older adults are more exposed to these words in everyday situations, and thus the words were not as salient to them. If these words did not strike them as interesting or noteworthy, they may have tended to concentrate on those words more interesting to them. This phenomenon has been supported in different age groups; younger adults have shown a preference for uncommon words when given the choice between evaluating the aesthetic value of a common word versus an uncommon word (Colman, Walley, \& Sluckin, 1975). Colman and colleagues found that uncommon words were rated as more aesthetically pleasing than common words. Therefore, the younger adults in the present study may have found the religious words to 
be more uncommon, unfamiliar, or interesting. For this reason younger adults may have concentrated more on the religious words, facilitating the memory process.

In the memory recognition task, younger adults recognized more words than did older adults, which again is consistent with theories of cognition throughout the life-span that state that memory is negatively related to age (Lindenberger \& Baltes, 1997). Negative words were recognized the most, which again could be the result of unfamiliarity. Although care was taken to ensure that the words on the list were suitable to both age groups and familiar to everyone, there inevitably were some types of words on the list that were less familiar than others. For instance, one is more apt to hear and use positive or neutral words in everyday conversation than negative words such as "killed" or "bomb." Nonetheless, these findings do not support the cognitive bias of optimism. In the age $\mathrm{x}$ type interaction, younger adults recognized more positive words, more negative words, more neutral words, and more religious words than the older adults. However, not all of these differences were significant; the difference in recognition of negative words was very small and not significant. Older adults, as a group, recognized negative words most frequently while younger adults, as a group, recognized negative words the least frequently. This was unexpected, as the older adults did indicate higher spirituality in comparison to the younger adults, yet the older adults recognized many of the negative words. Perhaps the older adults were uncomfortable with the task and unhappy to be engaging in memory exercises, resulting in increased attention to negativity.

When individual differences in memory were controlled for in the recall task and percentages were used, a main effect for word type remained, while the interaction between age and type of word remembered was no longer significant. Examining just the percentages of 
words recalled, religious words were recalled the most, followed by positive words, neutral words, and negative words.

In the memory recognition task with percentages used, religious words were the type that was most correctly recognized. The interaction between age and word type showed that younger adults recognized more of the positive words, more neutral words, and more religious words than the older adults, but fewer of the negative words. Older adults, parallel to the results of the recognition task using raw numbers, recognized had the highest proportion of negative words on the recognition worksheet. The same reason may also apply in this case; the older adults did not enjoy the task and may have concentrated on the negatives instead of the other types of words.

It is interesting to note that negative words are often the least frequently recalled type of word and the most frequently occurring type of word on the recognition task. This could relate to task difficulty. Perhaps the memory recognition tasks were too easy, resulting in everyone being able to recognize nearly every word on the list. The recall tasks were more difficult, so that in order to recall as many word as possible, participants selectively attended to those words most salient to them.

\section{Attendance at religious services}

Using the single item measure, participants who reported that they attend religious services often also reported higher levels of religiosity, as well as higher levels of optimism an unknown forces locus of control. The link between overall religiosity and attendance at religious services is obvious; one who is highly religious is more apt to attend services regularly. The relationship between attendance at religious services and optimism is in line with past research which states that mere attendance at religious services can have positive benefits to one's life in adolescence (Markstrom, 1999), younger adult groups (Kalil, Born, Kunz, \& Caudill, 2001) and 
older adult groups (Idler \& Kasl, 1997). In addition, those who attend religious services have a more unknown forces style of locus of control. This also makes intuitive sense based on other results of this study. The current study found a strong relationship between overall spirituality and unknown forces locus of control. Therefore, it is no surprise that because of the relationship between attendance at religious services and spirituality, there would also be a relationship between attendance at religious services and unknown forces locus of control. Religiosity vs. Spirituality

The comparison between religious individuals and spiritual individuals revealed that these groups of individuals are quite similar on some variables. Both highly religious individuals and highly spiritual individuals indicated high levels of spirituality, as measured by the overall Fetzer scale, and high levels of optimism. Furthermore, both of these groups indicated an association with the unknown forces locus of control.

Within each group, religious or spiritual, there were group differences. In the group of spiritual individuals, those reporting higher spirituality had lower scores on the internal subscale of the locus of control scale than those reporting lower spirituality. This difference did not arise in the religious group; highly religious individuals did not differ from those who reported lower religiosity. Thus, there are differences between the religious and spiritual groups on the internal locus of control subscale.

\section{Limitations}

The current study was limited by the use of self-report measures. These types of measures carry several sources of error (Judd, 1988). Particularly in the younger adult group, participants may have been in a hurry to get through and may not have answered accurately. The 
participants in the older adult group may have been more careful when completing the questionnaires.

Another limitation resided in the testing areas. Younger adults were brought into classrooms in Oglebay Hall and were tested in small groups of 5 or 10 individuals. Older adults were unwilling to come to Oglebay Hall, making it necessary for the researchers to test groups of older adult participants in large rooms in senior centers while various other activities were taking place in the background. This might have introduced additional noise into the design that interfered with their performance.

\section{Future Directions}

The results of the current study strongly support the notions that (1) older adults are more spiritual than younger adults, (2) high spirituality is related to high levels of optimism, (3) spirituality is related to an external locus of control, but only for the unknown forces locus of

control, and (4) spirituality, although it is related to optimism, does not appear to be related to the cognitive bias of optimism. The results do not lend any support as to how spirituality, as a positive life theme, may be linked to high levels of optimism. The hypothesis stated that it may be due to a unique style of cognitive processing, yet the results of this study also do not indicate that spirituality is linked to a unique or different style of cognitive processing. In the future, different types of cognitive tasks and different measures of spirituality should be used in order to further explore this hypothesis. 
Table 1

Properites of Measures

\begin{tabular}{lll}
\hline Measure & Number of items & Possible Range \\
\hline Fetzer - Overall & 32 & $32-153$ \\
Life Orientation Test & 8 & $0-16$ \\
Locus Of Control Scale & 8 & $0-48$ \\
$\quad$ Internal & 8 & $0-48$ \\
$\quad$ Chance & 8 & $0-48$ \\
$\quad$ Powerful Others & 8 & $0-48$ \\
$\quad$ Unknown Forces & 10 & $10-40$ \\
Self-Efficacy Scale & 10 & $10-40$ \\
Rosenberg Self-Esteem Scale & &
\end{tabular}

Note: LOC scales have +24 added to make the values positive 
Table 2

Means and Standard Deviations of the Dependent Variables

\begin{tabular}{|c|c|c|c|}
\hline Group & Measure & Mean & $\mathrm{SD}$ \\
\hline \multirow[t]{8}{*}{ Younger Adults } & Fetzer & 100.2 & 20.7 \\
\hline & Life Orientation Test & 19.0 & 6.2 \\
\hline & LOC: Internal & 35.5 & 5.6 \\
\hline & LOC: Chance & 23.2 & 11.6 \\
\hline & LOC: Powerful Others & 17.7 & 6.7 \\
\hline & LOC: Unknown Forces & 25.3 & 7.2 \\
\hline & Self-Efficacy Scale & 32.4 & 8.5 \\
\hline & Rosenberg Self-Esteem Scale & 32.4 & 5.2 \\
\hline \multirow[t]{8}{*}{ Older Adults } & Fetzer & 117.8 & 21.0 \\
\hline & Life Orientation Test & 20.3 & 4.6 \\
\hline & LOC: Internal & 32.4 & 5.0 \\
\hline & LOC: Chance & 23.1 & 6.2 \\
\hline & LOC: Powerful Others & 19.6 & 7.4 \\
\hline & LOC: Unknown Forces & 27.0 & 5.3 \\
\hline & Self-Efficacy Scale & 30.7 & 10.9 \\
\hline & Rosenberg Self-Esteem Scale & 31.1 & 4.5 \\
\hline
\end{tabular}

LOC $=$ locus of control

LOC scales have +24 added to make the values positive 
Table 3

Correlations Among the Dependent Variables

$\begin{array}{lccccccccc} & \mathrm{FET}^{2} & \mathrm{LOT}^{3} & \mathrm{INT}^{4} & \mathrm{CHA}^{5} & \mathrm{PO}^{6} & \mathrm{UF}^{7} & \mathrm{Seff}^{8} & \mathrm{Sest}^{9} \\ \text { Fetzer Scale } & 1.00 & .38^{* *} & -.13 & -.01 & -.30 & .50^{* *} & -.13 & .02 \\ \text { Life Orientation Test } & .38^{* *} & 1.00 & .19 & -.30^{* *} & -. .39^{* *} & .25^{*} & .21 & .41^{* *} \\ \text { Internal LOC } & -.13 & .12 & 1.00 & -.23^{*} & -.14 & .05 & .38^{* *} & .34 * * \\ \text { Chance LOC } & -.01 & -.30^{* *} & -.23 & 1.00 & .42^{* *} & .01 & -.34^{* *} & -.39^{* *} \\ \text { Powerful Others LOC } & -.30 & -.39^{* *} & -.14 & .42^{* *} & 1.00 & -.06 & -.17 & -.42^{* *} \\ \text { Unknown Forces LOC } & .50^{* *} & .25^{*} & .05 & .01 & .06 & 1.00 & -.21 & -.12 \\ \text { Self-Efficacy } & -.13 & .21 & .38^{* *} & -.34^{* *} & -.17 & -.21 & 1.00 & .28^{*} \\ \text { Self-Esteem } & .02 & .41^{* *} & .37 * * & -.39^{* *} & -.42^{* *} & -.11 & .28 & 1.00\end{array}$

$* \mathrm{p}<.05$

$* * \mathrm{p}<.01$

${ }^{1}$ Locus of control, ${ }^{2}$ Fetzer Scale, ${ }^{3}$ Life Orientation Test, ${ }^{4}$ Internal subscale of the locus of control scale, ${ }^{5}$ chance subscale of the locus of control scale, ${ }^{6}$ powerful others subscale of the locus of control scale, ${ }^{7}$ unknown forces subscale of the locus of control scale, ${ }^{8}$ Generalized Self-Efficacy Scale, ${ }^{9}$ Rosenberg Self-Esteem Scale 
Table 4

Means and Standard Deviations for the Recall Task

\begin{tabular}{llllll}
\hline & Positive & Negative & Neutral & Religious & Total \\
\hline Young Adults & $2.62(1.2)$ & $2.17(1.2)$ & $2.27(1.5)$ & $4.74(1.5)$ & $11.67(3.3)$ \\
Low spiritual & $2.32(1.4)$ & $2.08(1.1)$ & $2.48(1.5)$ & $4.28(1.7)$ & $12.60(3.4)$ \\
High spiritual & $2.93(1.3)$ & $2.27(1.4)$ & $2.07(1.5)$ & $5.20(2.0)$ & $13.80(2.7)$ \\
Older Adults & $2.11(1.8)$ & $1.90(1.8)$ & $1.60(1.5)$ & $2.80(2.0)$ & $8.30(6.1)$ \\
Low spiritual & $2.38(2.5)$ & $2.23(1.4)$ & $1.70(2.1)$ & $2.77(2.2)$ & $9.40(8.4)$ \\
High spiritual & $1.84(1.3)$ & $1.56(1.4)$ & $1.52(1.1)$ & $3.73(2.0)$ & $10.50(5.1)$ \\
\hline
\end{tabular}

Note: standard deviation in parentheses 
Table 5

Means and Standard Deviations for the Recognition Task

\begin{tabular}{llllll}
\hline & Positive & Negative & Neutral & Religious & Total \\
\hline Young Adults & $7.76(2.0)$ & $7.48(1.8)$ & $7.53(2.3)$ & $7.90(1.4)$ & $29.40(8.2)$ \\
Low spiritual & $7.12(2.0)$ & $6.70(2.9)$ & $7.00(2.3)$ & $7.60(1.4)$ & $29.80(8.8)$ \\
High spiritual & $8.40(1.5)$ & $8.00(1.4)$ & $8.06(2.2)$ & $8.20(1.3)$ & $34.80(5.1)$ \\
Older Adults & $5.04(2.7)$ & $6.77(2.7)$ & $4.76(2.7)$ & $6.20(2.7)$ & $21.85(9.6)$ \\
Low spiritual & $5.07(3.3)$ & $7.30(3.4)$ & $4.85(2.2)$ & $6.00(2.0)$ & $24.60(8.9)$ \\
High spiritual & $5.00(2.4)$ & $6.24(2.7)$ & $4.68(2.8)$ & $6.36(2.6)$ & $23.70(10.1)$ \\
\hline
\end{tabular}

Note: standard deviation in parentheses 
Table 6

Analysis of Variance for Word Type - Recall Task

\begin{tabular}{|c|c|c|c|c|c|}
\hline Source & $\mathrm{df}$ & $\begin{array}{l}\text { Mean } \\
\text { Square }\end{array}$ & $\mathrm{F}$ & $p$ & $\begin{array}{l}\text { partial } \\
\text { eta }^{2}\end{array}$ \\
\hline \multicolumn{6}{|c|}{ Between subjects } \\
\hline Age (A) & 1 & 51.54 & 8.30 & .005 & .101 \\
\hline Spirituality (S) & 1 & .00 & .00 & .997 & .000 \\
\hline$A \times S$ & 1 & 7.70 & 1.24 & .269 & .016 \\
\hline Error & 74 & 6.21 & & & \\
\hline \multicolumn{6}{|c|}{ Within subjects } \\
\hline Word type (W) & 3 & 51.60 & 30.28 & .001 & .291 \\
\hline $\mathrm{W} \times \mathrm{A}$ & 3 & 9.84 & 5.78 & .001 & .073 \\
\hline $\mathrm{W} \times \mathrm{S}$ & 3 & 2.33 & 1.37 & .253 & .019 \\
\hline $\mathrm{W} \times \mathrm{A} \times \mathrm{S}$ & 3 & 1.70 & .99 & .396 & .013 \\
\hline Error & 222 & 1.70 & & & \\
\hline
\end{tabular}


Table 7

Analysis of Variance for Word Type-Recognition Task

\begin{tabular}{|c|c|c|c|c|c|}
\hline Source & $\mathrm{df}$ & $\begin{array}{l}\text { Mean } \\
\text { Square }\end{array}$ & $\mathrm{F}$ & $p$ & $\begin{array}{l}\text { partial } \\
\text { eta }^{2}\end{array}$ \\
\hline \multicolumn{6}{|c|}{ Between subjects } \\
\hline Age (A) & 1 & 280.40 & 19.03 & .001 & .205 \\
\hline Spirituality (S) & 1 & 10.31 & .70 & .406 & .009 \\
\hline$A \times S$ & 1 & 27.26 & 1.85 & .178 & .024 \\
\hline Error & 74 & 14.73 & & & \\
\hline \multicolumn{6}{|c|}{ Within subjects } \\
\hline Word type (W) & 3 & 16.48 & 7.23 & .001 & .089 \\
\hline $\mathrm{W} \times \mathrm{A}$ & 3 & 17.08 & 7.50 & .001 & .092 \\
\hline $\mathrm{W} \times \mathrm{S}$ & 3 & 1.30 & .57 & .633 & .008 \\
\hline W x A x S & 3 & 2.63 & 1.16 & .327 & .015 \\
\hline Error & 222 & 2.78 & & & \\
\hline
\end{tabular}


Table 8

Analysis of Variance for Word Type-Recall Task-Percentage

\begin{tabular}{|c|c|c|c|c|c|}
\hline Source & $\mathrm{df}$ & $\begin{array}{l}\text { Mean } \\
\text { Square }\end{array}$ & $\mathrm{F}$ & $p$ & $\begin{array}{l}\text { partial } \\
\text { eta }^{2}\end{array}$ \\
\hline \multicolumn{6}{|c|}{ Between subjects } \\
\hline Age (A) & 1 & .41 & .34 & .561 & .005 \\
\hline Spirituality (S) & 1 & .95 & .77 & .382 & .010 \\
\hline$A \times S$ & 1 & 3.30 & 2.68 & .105 & .036 \\
\hline Error & 73 & 1.23 & & & \\
\hline \multicolumn{6}{|c|}{ Within subjects } \\
\hline Word type (W) & 3 & 4312.31 & 14.44 & .001 & .165 \\
\hline $\mathrm{W} \times \mathrm{A}$ & 3 & 576.61 & 11.93 & .126 & .026 \\
\hline $\mathrm{W} \times \mathrm{S}$ & 3 & 190.68 & 8.64 & .591 & .009 \\
\hline $\mathrm{W} \times \mathrm{A} \times \mathrm{S}$ & 3 & 140.55 & .47 & .703 & .006 \\
\hline Error & 219 & 298.67 & & & \\
\hline
\end{tabular}


Table 9

Analysis of Variance for Word Type-Recognition Task-Percentage

\begin{tabular}{|c|c|c|c|c|c|}
\hline Source & $\mathrm{df}$ & $\begin{array}{l}\text { Mean } \\
\text { Square }\end{array}$ & $\mathrm{F}$ & $p$ & $\begin{array}{l}\text { partial } \\
\text { eta }^{2}\end{array}$ \\
\hline \multicolumn{6}{|c|}{ Between subjects } \\
\hline Age (A) & 1 & 262.24 & .50 & .480 & .007 \\
\hline Spirituality (S) & 1 & 313.93 & .60 & .440 & .008 \\
\hline $\mathrm{A} \times \mathrm{S}$ & 1 & 302.57 & .58 & .448 & .008 \\
\hline Error & 74 & 520.00 & & & \\
\hline \multicolumn{6}{|c|}{ Within subjects } \\
\hline Word type (W) & 3 & 589.79 & 6.48 & .001 & .081 \\
\hline $\mathrm{W} \times \mathrm{A}$ & 3 & 519.38 & 5.70 & .001 & .072 \\
\hline $\mathrm{W} \times \mathrm{S}$ & 3 & 49.9 & 8.55 & .649 & .007 \\
\hline $\mathrm{W} \times \mathrm{A} \times \mathrm{S}$ & 3 & 108.6 & 31.20 & .313 & .016 \\
\hline Error & 222 & 91.02 & & & \\
\hline
\end{tabular}


Table 10

Subscales of the Fetzer Multidimensional Measurement of Religiousness/Spirituality

\begin{tabular}{lcc}
\hline Subscale & Mean & Standard Deviation \\
\hline Daily Spiritual Experiences & 25.45 & 6.57 \\
Values/Beliefs & 6.91 & 1.09 \\
Forgiveness & 9.69 & 1.78 \\
Private Religious Experiences & 18.40 & 8.40 \\
Religious and Spiritual Coping & 20.93 & 3.37 \\
Religious Support & 13.03 & 1.97 \\
Organizational Religiosity & 6.06 & 2.70 \\
Overall & 5.55 & 1.46 \\
\hline
\end{tabular}


Figure 1. Mean number of words recalled in the memory recall task by age and spirituality.

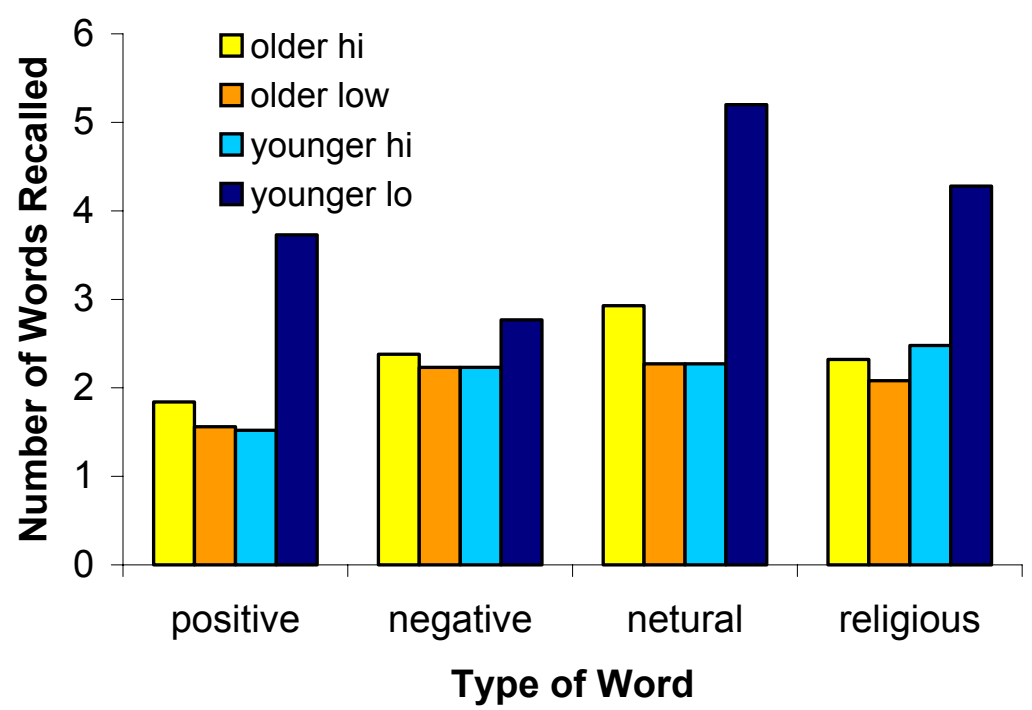


Figure 2. Mean number of words recognized in the memory recognition task by age and spirituality.

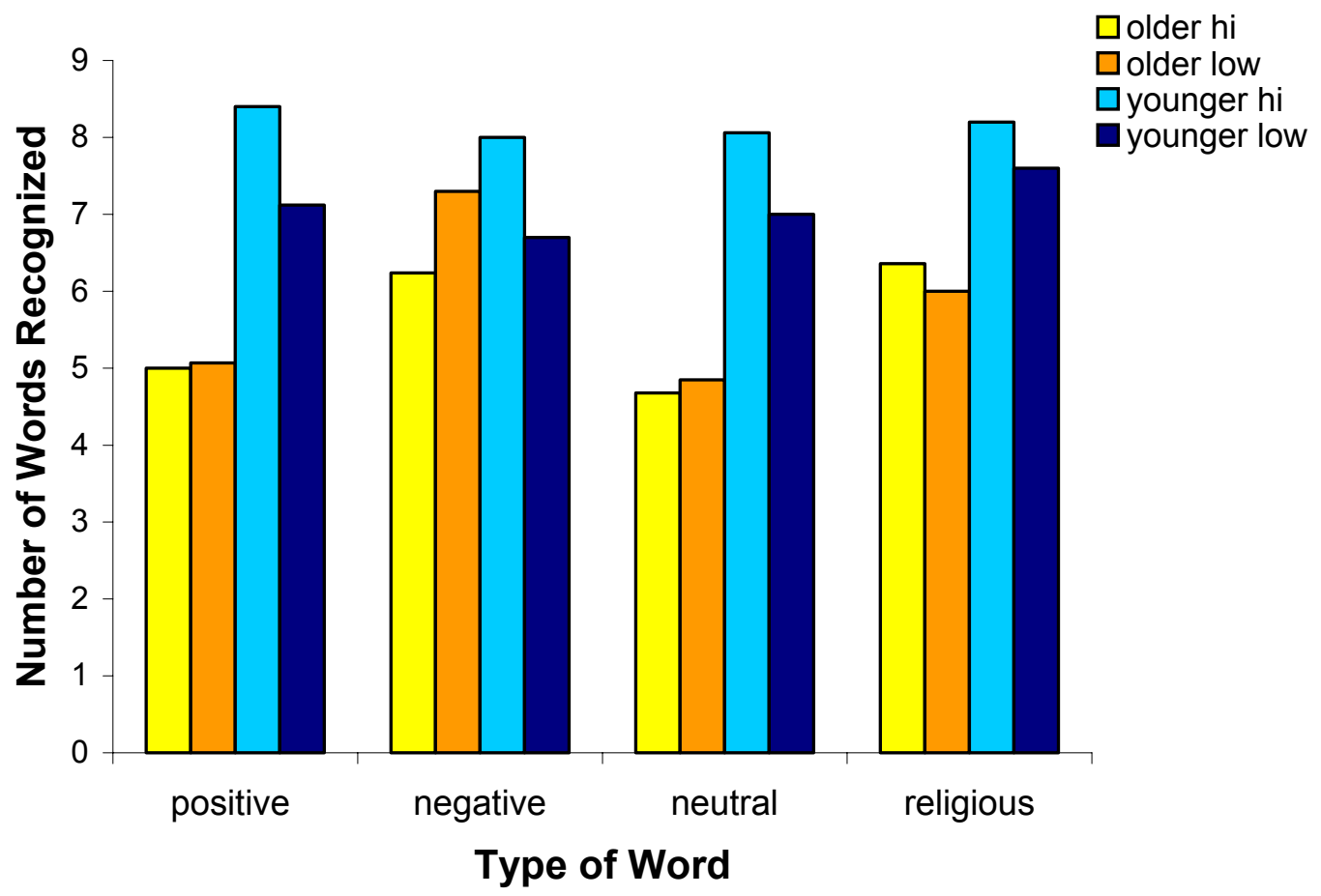


Figure 3. Percentage of words recalled in the memory recall task.

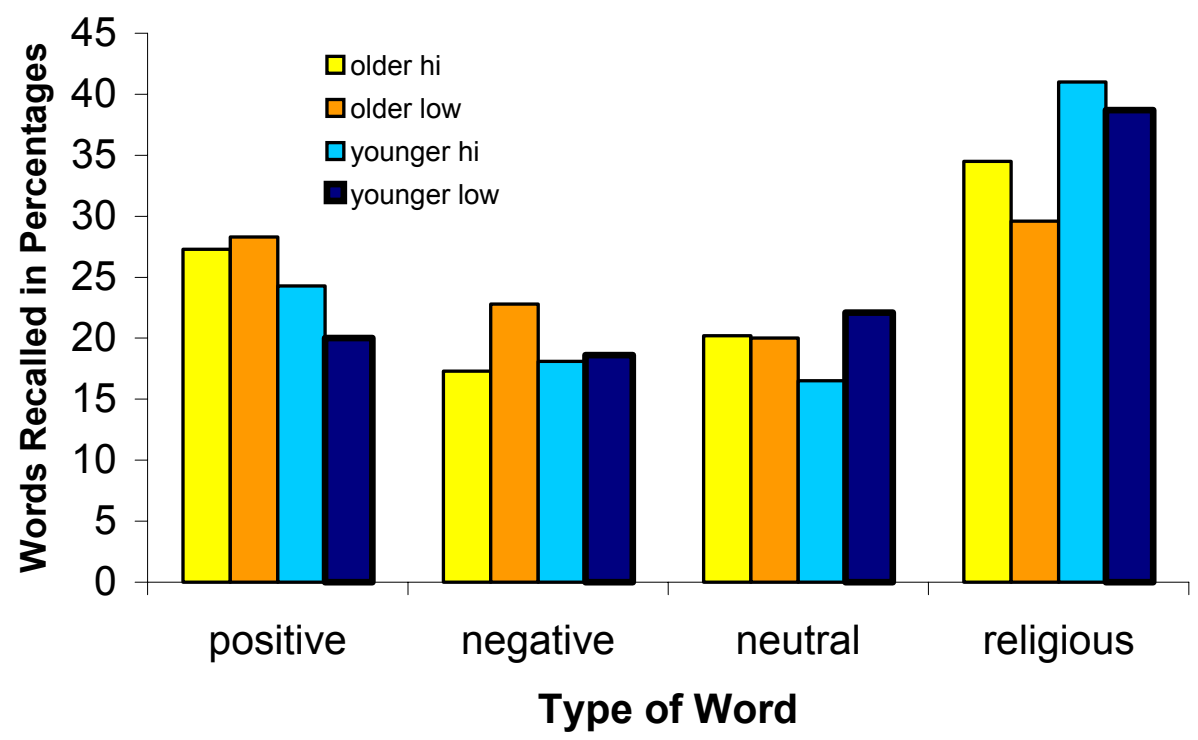


Figure 4. Percentages of words recognized in the memory recognition task by age and spirituality.

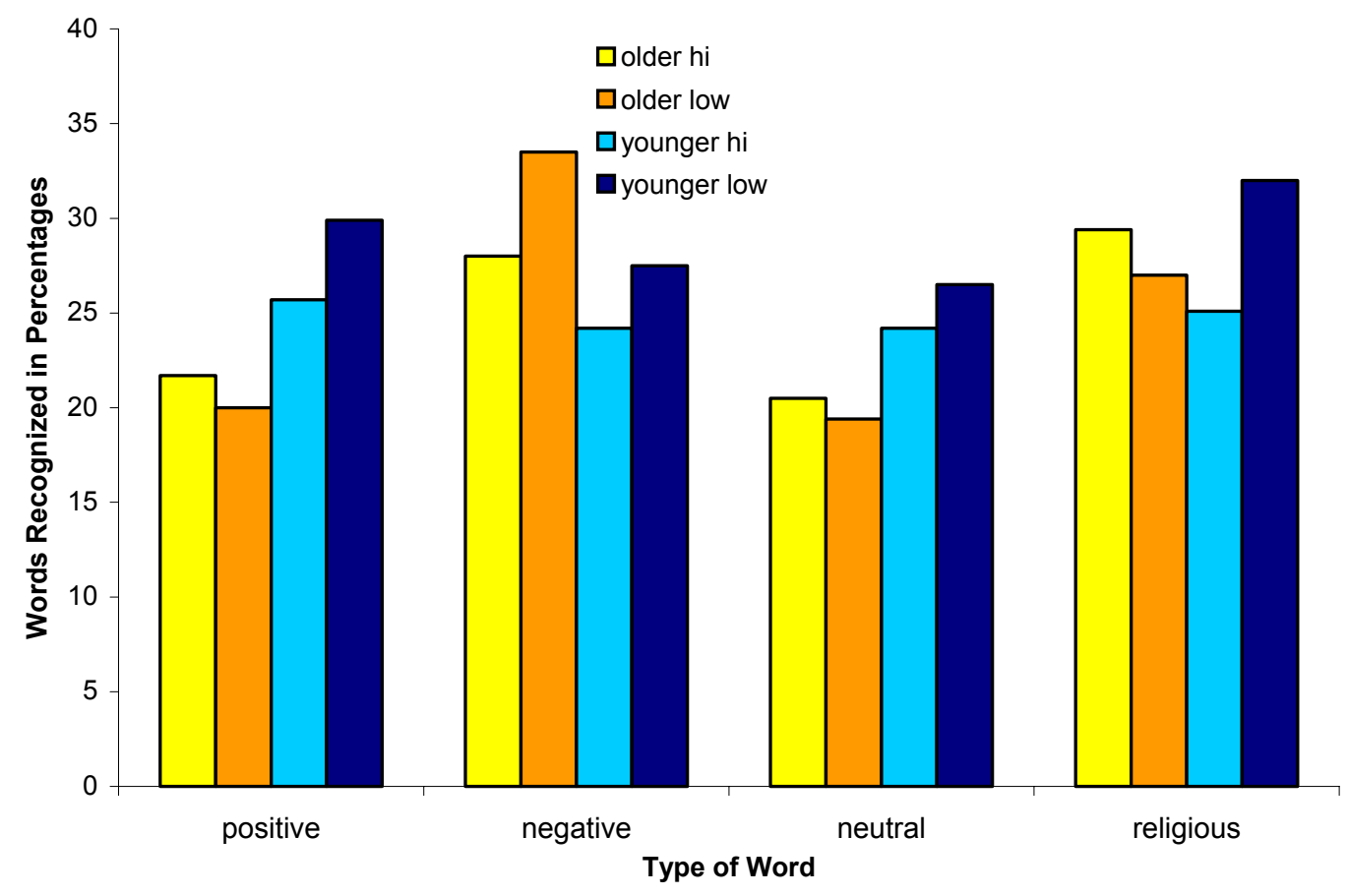




\section{References}

Adams, T. B., Bezner, J. R., Drabbs, M. E., Zambarano, R. J., \& Steinbardt, M. A. (2000). Conceptualization and measurement of the spiritual and psychological dimensions of wellness in a college population. Journal of American College Health, 48, 165-173.

Aronson, E., Wilson, T. D., \& Akert, R. M. (2002). Social Psychology (4 ${ }^{\text {th }}$ ed.), Upper Saddle River, NJ: Prentice Hall.

Baltes, P. B., \& Finnel, R. B. (1992). Wise and otherwise. Natural History, 101, 50-52.

Benight, C. C., Freyaldenhoven, R. W., Hughes, J., Ruiz, J. M., Aoschke, T. A. \& Lovallo, W. R. (2000). Coping self-efficacy and psychological distress following the Oklahoma City bombing. Journal of Applied Social Psychology, 30(7), 1331-1334.

Black, H. (1999). Life as gift; spiritual narratives of elderly African American women living in poverty. Journal of Aging Studies, 13, 441-455.

Cloitre, M. \& Liebowitz, M. R. (1991). Memory bias in panic disorder; an investigation of the cognitive avoidance hypothesis. Cognitive Therapy and Research, 15, 371-386.

Colman, A. M., Walley, M., \& Sluckin, W. (1975). Preferences for common words, uncommon words and non-words by children and young adults. British Journal of Psychology, 66(4), 481-486.

Dobbs, A. R., \& Rule, B. G. (1989). Adult age differences in working memory. Psychology and Aging, 4, 500-503.

Dougall, A. L., Hyman, K. B., Hayward, M. C., McFeely S., \& Baum, A. (2001). Optimism and traumatic stress: The importance of social support and coping. Journal of Applied Social Psychology, 31(2), 223-245. 
Elliott, T. R., Godshall, F. J., Herrick, S. M., Witty, T. E., \& Spruell, M. (1991). Problem-solving appraisal and psychological adjustment following spinal cord injury. Cognitive Therapy and Research, 15, 387-398.

Helminiak, D. A. (2001). Treating spiritual issues in secular psychotherapy. Counseling and Values, 45(3), 163-189.

Hoeltje, C. O., Zubrick, S. R., Silburn, S. R., \& Garton, A. F. (1996). Generalized self-efficacy: Family and adjustment correlates. Journal of Clinical and Child Psychology, 25(4), 446453.

Humphrey, D. G., \& Kramer, A. F. (1999). Age-related differences in perceptual organization and selective attention: implications for display segmentation and recall performance. Experimental Aging Research, 25, 1-26.

Idler, E. L., \& Kasl, S. V. (1997). Relationships among disabled and nondisabled persons: Attendance at religious services as a predictor of course of disability. Journal of Gerontoloty: Series B: Psychological Sciences and Social Sciences, 52B, S306-S316.

Ita, D. J., (1995). Testing of a causal model: Acceptance of death in hospice patients. Omega: Journal of Death and Dying, 32(2), 81-92.

John E. Fetzer Institute. (1999, October). Multidimensional measurement of religiousness/spirituality for use in health research: A report of the Fetzer Institute/National Institute on Aging Workshop Group.

Johnson, J. G., Crofton, A., \& Feinstein, S. B. (1996). Enhancing attributional style with positive life events predict increased hopefulness among depressed psychiatric inpatients. Motivation and Emotion, 20(4), 285-297. 
Kalil, A., Born, C. E., Kunz, J., \& Caudill, P. J. (2001). Life stressors, social support, and depressive symptoms among first time welfare recipients. American Journal of Community Psychology, 29(2), 355-369.

Kaspi, S. P., McNally, R. J., \& Amir, N. (1995). Cognitive processing of emotional information in posttraumatic stress disorder. Cognitive Therapy and Research, 19(4), 433-444.

Knox, D. (1998). Religiosity and spirituality among college students. College student Journal, $32,430-432$.

Krause, N. \& Van Tran, T. (1989). Stress and religious involvement among older blacks. Journal of Gerontology, 44, S4-13.

Laumann, L. L. (1999). Adult age differences in vocabulary acquisition as a function of individual differences in working memory and prior knowledge, doctoral dissertation, West Virginia University, Morgantown.

Levenson, H. (1973). Multidimensional locus of control in psychiatric patients. Journal of Counseling and Clinical Psychology, 41, 397-404.

Lindenberger, U., \& Baltes, P. B. (1997). Intellectual functioning in old and very old age: Crosssectional results from the Berlin Aging Study. Psychology and Aging, 12(3), 410-432.

Markstrom, C. A. (1999). Religious involvement and adolescent psychosocial development. Journal of Adolescence, 22(2), 205-221.

Mattis, J. S. (2000). African American women's definitions of spirituality and religiosity. Journal of Black Psychology, 26, 101-123.

McFadden, S. H. (1996). Religion, spirituality, and aging. In J. E. Birren \& K. W. Schaie (Eds.), Handbook of the Psychology of Aging, $4^{\text {th }}$ edition (pp. $\left.162-177\right)$. San Diego: Academic Press. 
McNally, R. J. \& Clancy, S. A. (1998). Directed forgetting of trauma cues in adult survivors of childhood sexual abuse with and without posttraumatic stress disorder. Journal of Abnormal Psychology, 107, 596-602.

McNally, R. J. \& Kaspi, S. P., Riemann, B. C., \& Zeitlin, S. B. (1990). Selective processing of threat cues in posttraumatic stress disorder. Journal of Abnormal Psychology, 99, 398402.

McNally, R. J., Otto, M. W., Hornig, C. D., \& Deckersbach, T. (2001). Cognitive bias in panic disorder: A process approach to automaticity. Cognitive Therapy and Research, 25(3), $335-347$.

Miller, L. M. S., \& Lachman, S. E. (1999). The sense of control and cognitive aging: Toward a model of mediational processes. In T. M. Hess and F. Blanchard-Fields (Eds). Social Cognition and Aging. (pp. 17-41). San Diego: Academic Press.

Mitchell, C. E. (1988). Paralleling cognitive and moral development with spiritual development and denominational choice. Psychology, A Journal of Human Behavior, 25, 1-9.

Mynard, H., Joseph, S., \& Alexander, J. (2000) Peer-victimisation and posttraumatic stress in adolescents. Personality and Individual Differences, 29(5), 815-821.

Nier, J. A., Mottola, G. R., \& Gaertner, S. L. (2000). The O. J. Simpson criminal verdict as a racially symbolic event: A longitudinal analysis of racial attitude change. Personality and Social Psychology Bulletin, 26(4), 507-516.

Needles, D. J., \& Abramson, L. Y. (1990). Positive life events, attributional style, and hopefulness: Testing a model of recovery from depression. Journal of Abnormal Psychology, 99(2), 156-165. 
Nosek, M. A. (2001). Psychospiritual aspects of sense of self in women with physical disabilities. Journal of Rehabilitation, 67(1), 20-26.

Nunn, G. D. (1994). Adult learners' locus of control, self-evaluation, and learning temperament as a function of age and gender. Journal of Instructional Psychology, 21, 260-264.

Park. J. H., Meyers, L. S., \& Czar, G. C. (1998). Religiosity and spirituality: an exploratory analysis using the CPI 3-vector model. Journal of Social Behavior and Personality, 13, $541-553$.

Pettit, J. W., \& Joiner, T. E. (2001). Negative life events predict negative feedback seeking as a function of impact on self-esteem. Cognitive Therapy and Research, 25(6), 733-741.

Plante, T. G., Yancey, S., Sherman, A., \& Guertin, M. (2000). The association between strength of religious faith and psychological functioning. Pastoral Psychology, 48, 405-412.

Price, P. C., Pentecost, H. C., \& Voth, R. D. (2002). Perceived event frequency and the optimistic bias: Evidence for a two-process model of personal risk judgement. Journal of Experimental SocialPsychology, 38(3), 242-252.

Pritt, A. (1998). Spiritual correlates of reported sexual abuse among Mormon women. Journal for the Scientific Study of Religion, 37, 273-285.

Richards, D. G. (1990). A “universal forces" dimension of locus of control in a population of spiritual seekers. Psychological Reports, 67, 847-850.

Robinson, J. P., \& Shaver, P. R. (1980). Measures of Social Psychological Attitudes (revised edition). Ann Arbor: Institute for Social Research.

Scheier, M. F., \& Carver, C. S. (1987). Dispositional optimism and physical wellbeing: the influence of generalized outcome expectancies on health. Journal of Personality, 55,_170210. 
Scheier, M. F., Carver C. S., \& Bridges, M. W. (1994). Distinguishing optimism from neuroticism (and trait anxiety, self-mastery, and self-esteem): A reevaluation of the life orientation test. Journal of Personality and Social Psychology, 67(6), 1063-1078.

Schutte, J. W., \& Hosch, H. M. (1998). Optimism, religiosity, and neuroticism; a cross-cultural study. Personality and Individual Differences, 20, 239-244.

Schwarzer, R., Baßler, J., Kwiatek, P., Schroder, K., \& Zhang, J. X. (1997). The assessment of optimistic self-beliefs; comparison of the German, Spanish, and Chinese versions of the general self-efficacy scale. Applied Psychology: An International Review, 46, 69-88.

Schweizer, K., Beck-Seyffer, A., \& Schneider, R. (1999). Cognitive bias of optimism and its influence on psychological well being. Psychological Reports, 84, 627-636.

Shaw, B., \& Krause, N. (2001). Exploring race variations in aging and personal control. Journals of Gerontology Series-B: Psychological Sciences and Social Sciences, 56B, 1119-1124.

Slavik, S., \& Croake, J. (2001). Feelings and spirituality: A holistic perspective. Journal of Individual Psychology, 57(4), 354-362.

Smith, A. D. (1996). Memory. In James E. Birren \& K. Warner Schaie (Eds.), Handbook of the Psychology of Aging, $4^{\text {th }}$ Edition (pp. 236-250). San Diego: Academic Press.

Taylor, R. J. (1999). Subjective religiosity among African Americans: a synthesis of findings from 5 national samples. Journal of Black Psychology, 25,_524-544.

Thorndike, E. L., \& Lorge, I. (1944). The teacher's word book of 30,000 words. New York: Teachers College Press. 
Waite P. J., Hawks, S. R., \& Gast, J. A. (1999). The relationship between spiritual well being and health behaviors. American Journal of Health Promotion, 13, 159-162.

Williamson, D. A. \& Muller, S. L. (1999). Cognitive bias in eating disorders; implications for theory and treatment. Behavior Modification, 23, 556-578.

Wingfield, A., Stine, E. L., Lahar, C. J., \& Aberdeen, J. S. (1988). Does the capacity of working memory change with age? Experimental Aging Research, 14, 103-107.

Wink, P., \& Dillon, M. (2002). Spiritual development across the adult life course: Findings from a longitudinal study. Journal of Adult Development,9(1), 79-94. 


\section{Appendix A}

\section{$\underline{\text { RECOGNITION }}$ \\ Positive \\ EXCITE \\ HOPEFUL \\ CHEERFUL \\ LAUGHTER \\ GIFT \\ ANGEL \\ LOVE \\ FORTUNE \\ HAPPY \\ SMILE}

Word Lists Used in the Memory Tasks

Negatvie

NERVOUS

ILLNESS

SICK

HELPLESS

CANCER

POISON

DISEASE

CORPSE

ACCIDENT

TUMOR

Neutral

STEADY

BOOK

POWDER

BOXES

SLEEVE

BUTTON

BOAT

BASKET

METAL

MIRROR

Religious

FAITH

SIN

SAINT

TEMPTATION

LAMB

STABLE

FORBIDDEN

DOVE

WINE

SACRIFICE 
Appendix A continued

\section{$\underline{\text { RECALL }}$}

Positive

BIRD

THANK

POEM

QUIET

KISS

ENJOY

PEACE

BEAUTY

PLAY

SUNNY

Negative

STINGY

LONELY

ULCER

HUNGRY

SLAVE

DIRTY

KILLED

WRECK

BOMB

BEGGAR

Netural

EVENT

IMPARTIAL

SLEEPY

CLOCK

FACT

ANKLE

SHOE

THUMB

FARMER

PITCH

Religious

CROSS

BURN

WORSHIP

CRUCIFY

PRAY

SERPENT

HALO

REPENT

WINGS

THORNS 


\section{Appendix B}

\section{Brief Multidimensional Measurement of Religiousness/Spirituality}

Fetzer Institute

\section{Daily Spiritual Experiences}

The following questions deal with possible spiritual experiences. To what extent can you say you experience the following:

1. I feel God's presence.

1 - Many times a day

2 - Every day

3 - Most days

4 - Some days

5 - Once in a while

6 - Never or almost never

2. I find strength and comfort in my religion.

1 - Many times a day

2 - Every day

3 - Most days

4 - Some days

5 - Once in a while

6 - Never or almost never

3. I feel deep inner peace or harmony.

1 - Many times a day

2 - Every day

3 - Most days

4 - Some days

5 - Once in a while

6 - Never or almost never

4. I desire to be closer to or in union with God.

1 - Many times a day

2 - Every day

3 - Most days

4 - Some days

5 - Once in a while

6 - Never or almost never 
5. I feel God's love for me, directly or through others.

1 - Many times a day

2 - Every day

3 - Most days

4 - Some days

5 - Once in a while

6 - Never or almost never

6. I am spiritually touched by the beauty of creation.

1 - Many times a day

2 - Every day

3 - Most days

4 - Some days

5 - Once in a while

6 - Never or almost never

\section{Values/Beliefs}

7. I believe in a God who watches over me.

1 - Strongly agree

2 - Agree

3 - Disagree

4 - Strongly disagree

8. I feel a deep sense of responsibility for reducing pain and suffering in the world.

1 - Strongly agree

2 - Agree

3 - Disagree

4 - Strongly disagree

\section{Forgiveness}

Because of my religious or spiritual beliefs:

9. I have forgiven myself for things that I have done wrong.

1 - Always or almost always

2 - Often

3 - Seldom

4 - Never

10. I have forgiven those who hurt me.

1 - Always or almost always

2 - Often

3 - Seldom

4 - Never 
11. I know that God forgives me.

1 - Always or almost always

2 - Often

3 - Seldom

4 - Never

\section{Private Religious Practices}

12. How often do you pray privately in places other than at church or synagogue?

1 - More than once a day

2 - Once a day

3 - A few times a week

4 - Once a week

5 - A few times a month

6 - Once a month

7 - Less than once a month

8 - Never

13. Within your religious or spiritual tradition, how often do you meditate?

1 - More than once a day

2 - Once a day

3 - A few times a week

4 - Once a week

5 - A few times a month

6 - Once a month

7 - Less than once a month

8 - Never

14. How often do you watch or listen to religious programs on TV or radio?

1 - More than once a day

2 - Once a day

3 - A few times a week

4 - Once a week

5 - A few times a month

6 - Once a month

7 - Less than once a month

8 - Never 
15. How often do you read the Bible or other religious literature?

1 - More than once a day

2 - Once a day

3 - A few times a week

4 - Once a week

5 - A few times a month

6 - Once a month

7 - Less than once a month

8 - Never

16. How often are prayers or grace said before or after meals in your home?

1 - At all meals

2 - Once a day

3 - At least once a week

4 - Only on special occasions

5 - Never

\section{Religious and Spiritual Coping}

Think about how you try to understand and deal with major problems in your life. To what extent is each of the following involved in the way you cope?

17. I think about how my life is part of a larger spiritual force.

$$
\begin{aligned}
& 1 \text { - A great deal } \\
& 2 \text { - Quite a bit } \\
& 3 \text { - Somewhat } \\
& 4 \text { - Not at all }
\end{aligned}
$$

18. I work together with God as partners.

$$
\begin{aligned}
& 1 \text { - A great deal } \\
& 2 \text { - Quite a bit } \\
& 3 \text { - Somewhat } \\
& 4 \text { - Not at all }
\end{aligned}
$$

19. I look to God for strength, support and guidance.

$$
\begin{aligned}
& 1 \text { - A great deal } \\
& 2 \text { - Quite a bit } \\
& 3 \text { - Somewhat } \\
& 4 \text { - Not at all }
\end{aligned}
$$

20. I feel God is punishing me for my sins or lack of spirituality.

$$
\begin{aligned}
& 1 \text { - A great deal } \\
& 2 \text { - Quite a bit } \\
& 3 \text { - Somewhat } \\
& 4 \text { - Not at all }
\end{aligned}
$$


21. I wonder whether God has abandoned me.

1 - A great deal

2 - Quite a bit

3 - Somewhat

$4-$ Not at all

22. I try to make sense of the situation and decide what to do without relying on God.

1 - A great deal

2 - Quite a bit

3 - Somewhat

$4-$ Not at all

23. To what extent is your religion involved in understanding or dealing with stressful situations in any way?

$1-$ Very involved

2 - Somewhat involved

3 -Not very involved

4 - Not involved at all

\section{Religious Support}

These questions are designed to find out how much help the people in your congregation would provide if you need it in the future.

24. If you were ill, how much would the people in your congregation help you out?

1 - A great deal

2 - Some

3 - A little

4 - None

25. If you had a problem or were faced with a difficult situation, how much comfort would the people in your congregation be willing to give you?

$1-$ A great deal

2 - Some

3 - A little

4 - None

26. How often do the people in your congregation make too many demands on you?

1 - Very often

2 - Fairly often

3 - Once in a while

4 - Never 
27. How often are the people in your congregation critical of you and the things you do? 1 - Very often

2 - Fairly often

3 - Once in a while

4 - Never

\section{Religious/Spiritual History}

28. Did you ever have a religious or spiritual experience that changed your life?

No

Yes

IF YES: How old were you when this experienced occurred?

29. Have you ever had a significant gain in your faith?

No

Yes

IF YES: How old were you when this occurred?

30. Have you ever had a significant loss in your faith?

No

Yes

IF YES: How old were you when this occurred?

\section{Commitment}

31. I try hard to carry my religious beliefs over into all my other dealings in life.

1 - Strongly agree

2 - Agree

3 - Disagree

4 - Strongly agree

32. During the last year, about how much was the average monthly contribution of your household to your congregation or to religious causes? $\$$ OR \$ per year per month

33. In an average week, how many hours do you spend in activities on behalf of your church or activities that you do for religious or spiritual reasons? 


\section{Organizational Religiousness}

34. How often do you go to religious services?

1 - More than once a week

2 - Every week or more often

3 - Once or twice a month

4 - Every month or so

5 - Once or twice a year

6 - Never

35. Besides religious services, how often do you take part in other activities at a place of worship?

1 - More than once a week

2 - Every week or more often

3 - Once or twice a month

4 - Every month or so

5 - Once or twice a year

6 - Never

\section{Religious Preference}

36. What is you current religious preference?

If Protestant, which specific denomination is that?

\section{Overall Self-Ranking}

37. To what extent do you consider yourself a religious person?

1 - Very religious

2 - Moderately religious

3 - Slightly religious

$4-$ Not religious at all

38. To what extent do you consider yourself a spiritual person?

1 - Very spiritual

2 - Moderately spiritual

3 - Slightly spiritual

4 - Not spiritual at all 


\section{Appendix C}

\section{Life Orientation Test}

(Scheier \& Carver, 1987)

Please indicate if you strongly agree (SA), agree (A), are neutral (N), disagree (D) or strongly disagree (SD) with the following statements:

In uncertain times, I usually expect the best.

If something can go wrong for me, it will.

I always look on the bright side of things.

I'm always optimistic about my future.

I hardly ever expect things to go my way.

Things never work out the way I want them to.

I'm a believer in the idea that "every cloud has a silver lining."

I rarely count on good things happening to me. $\begin{array}{lllll}\text { SA } & \text { A } & \mathrm{N} & \mathrm{D} & \mathrm{SD}\end{array}$

$\begin{array}{lllll}4 & 3 & 2 & 1 & 0\end{array}$

$\begin{array}{lllll}4 & 3 & 2 & 1 & 0\end{array}$

$\begin{array}{lllll}4 & 3 & 2 & 1 & 0\end{array}$

$\begin{array}{lllll}4 & 3 & 2 & 1 & 0\end{array}$

$\begin{array}{lllll}4 & 3 & 2 & 1 & 0\end{array}$

$\begin{array}{lllll}4 & 3 & 2 & 1 & 0\end{array}$

$\begin{array}{lllll}4 & 3 & 2 & 1 & 0\end{array}$

$\begin{array}{lllll}4 & 3 & 2 & 1 & 0\end{array}$




\author{
Appendix D \\ Levenson's and Richards' Locus of Control Scales \\ Multidimensional Locus of Control \\ (Levenson, 1989)
}

Please indicate whether you:

\begin{tabular}{|c|c|c|}
\hline agree & & $\begin{array}{l}\text { SA: Strongly Agree } \\
\text { MA: Moderately Agre }\end{array}$ \\
\hline $\begin{array}{l}\text { MD: Moderately Disagree } \\
\text { D: Disagree }\end{array}$ & N: Neut & $\begin{array}{c}\text { MA: Moderately } \\
\text { A: Agree }\end{array}$ \\
\hline
\end{tabular}

1. Whether or not I get to be a leader depends mostly on my ability.
SD
MD
D N
A
MA SA

2. To a great extent, my life is controlled by accidental happenings.

SD $\quad M \quad$ D $\quad \mathrm{N} \quad \mathrm{A} \quad \mathrm{MA} \quad \mathrm{SA}$

3. I feel like what happens in my life is mostly determined by powerful people.
SD MD
D $\quad \mathrm{N}$
A $\quad$ MA SA

4. My behavior will determine what will happen in my life.
SD MD
D N
A MA SA

5. When I make plans, I am almost certain to make them work.
SD MD
$\mathrm{D} \quad \mathrm{N}$
A MA SA

6. Often, there is no chance of protecting my personal interests from bad luck happenings.
SD MD
D N
A $\quad$ MA SA

7. When I get what I want, it's usually because I'm lucky.
SD MD
D N
A
MA SA

8. Even if I were a good leader, I would not be made a leader unless I play up to those in positions of power.
SD MD
D N
A $\quad$ MA SA

9. How many friends I have depends on how nice a person I am.
SD MD
D
$\mathrm{N}$
A MA SA

10. I have often found that what is going to happen will happen.
SD
MD
D N
A MA SA

11. My life is chiefly controlled by powerful others.

SD $\begin{array}{llllll}\text { MD } & \mathrm{D} & \mathrm{N} & \mathrm{A} & \mathrm{MA} & \mathrm{SA}\end{array}$ 
12. It is impossible for anyone to say how long I'll be in the hospital.
SD MD
D N
A
MA SA

13. People like myself have very little chance of protecting our personal interests when they conflict with those of powerful other people.
SD MD
D N
A MA SA

14. It's not always wise for me to plan too far ahead because many things turn out to be a matter of good or bad fortune.
$\mathrm{SD}$
MD
$\mathrm{D} \quad \mathrm{N}$
A $\quad$ MA SA

15. Getting what I want means I have to please those people above me.
SD MD
D N
A MA SA

16. Whether or not I get to be a leader depends on whether I'm lucky enough to be in the right place at the right time.
SD MD
D N
A $\quad$ MA SA

17. If important people were to decide they didn't like me, I probably wouldn't make many friends.
SD MD
D N
A $\quad$ MA SA

18. I can pretty much determine what will happen in my life.
SD
MD
D N
A MA SA

19. I am usually able to protect my personal interests.
SD MD
$\mathrm{D} \quad \mathrm{N}$
A MA SA

20. How soon I leave the hospital depends on other people who have power over me.
SD MD
D N
A
MA SA

21. When I get what I want, it's usually because I worked hard for it.
SD MD
D N
A
MA SA

22. In order to have my plans word, I make sure that they fit in with the desires of people who have power over me.
SD MD
D N
A $\quad$ MA SA

23. My life is determined by my own actions.
SD MD
D
$\mathrm{N}$
A MA SA

24. It's chiefly a matter of fate whether or not I have a few friends or many friends.
SD
MD
D
$\mathrm{N}$
A MA SA 


\section{Richard's Unknown Forces Locus of Control Scale (Richards, 1990)}

25. The creative force in the universe continues to play a major role in determining what will happen in my life.
SD MD D
$\mathrm{N}$
A $\quad$ MA SA

26. Events in my life are influenced by connections among all of us that are often not apparent.
SD
MD
D N
A $\quad$ MA SA

27. There is a meaningful order in the words, beyond chance, which guides my life.
SD MD
D N
A $\quad$ MA SA

28. The higher level of understanding of my spiritual self may override my conscious desires.

SD $\quad$ MD $\quad \mathrm{D} \quad \mathrm{N} \quad \mathrm{A} \quad \mathrm{MA} \quad \mathrm{SA}$

29. My success depends on the degree to which I am in accord with universal principles.
$\mathrm{SD}$
MD
$\mathrm{D} \quad \mathrm{N}$
A MA SA

30. I may at times need to yield my personal control and that of others to a higher moral law.
SD MD
D N
A $\quad$ MA SA

31. Whether or not someone becomes my friend depends on our attunement at a spiritual level.

SD $\quad$ MD $\quad \mathrm{D} \quad \mathrm{N} \quad \mathrm{A} \quad \mathrm{MA} \quad \mathrm{SA}$

32. Whether or not I become a leader depends on the nature of my ideals and my faithfulness to those ideals.

SD $\quad$ MD $\quad \mathrm{D} \quad \mathrm{N} \quad \mathrm{A} \quad \mathrm{MA} \quad \mathrm{SA}$




\section{Appendix E}

The Generalized Self-Efficacy Scale

(Schwarzer et al., 1997)

1. I can always manage to solve difficult problems

$\begin{array}{ccll}\text { Not at all } & \text { Barely } & \text { Moderately } & \text { Exactly } \\ \text { True } & \text { True } & \text { True } & \text { True }\end{array}$
if I try hard enough.

$\begin{array}{llll}1 & 2 & 3 & 4\end{array}$

2. If someone opposes me, I can find means and ways to get what I want.

$\begin{array}{llll}1 & 2 & 3 & 4\end{array}$

3. It is easy for me to stick to my aims and accomplish my goals.

$\begin{array}{llll}1 & 2 & 3 & 4\end{array}$

4. I am confident that I could deal efficiently with unexpected events.

$\begin{array}{llll}1 & 2 & 3 & 4\end{array}$

5. Thanks to my resourcefulness, I know how to handle unforeseen events.

$\begin{array}{llll}1 & 2 & 3 & 4\end{array}$

6. I can solve most problems if I invest the necessary effort. $\quad \begin{array}{llll}1 & 2 & 3 & 4\end{array}$

7. I can remain calm when facing difficulties because I can rely on my coping abilities.

$\begin{array}{llll}1 & 2 & 3 & 4\end{array}$

8. When I am confronted with a problem, I can usually find several solutions.

$\begin{array}{llll}1 & 2 & 3 & 4\end{array}$

9. If I am in a bind, I can usually think of something to do. $\quad \begin{array}{llll}1 & 2 & 3\end{array} 4$

10. No matter what comes my way, I'm usually able to handle it. $\begin{array}{lllll}1 & 2 & 3 & 4\end{array}$ 


\section{Appendix F \\ Rosenberg's Self Esteem Scale \\ (Rosenberg, 1965)}

1. I feel that I'm a person of worth, at least on an equal basis with others.

Strongly agree Agree Disagree Strongly disagree

2. I feel that I have a number of good qualities.

Strongly agree Agree Disagree Strongly disagree

3. All in all, I am inclined to feel that I am a failure.

Strongly agree Agree Disagree Strongly disagree

4. I am able to do things as well as most other people.

Strongly agree Agree Disagree Strongly disagree

5. I feel I do not have much to be proud of.

Strongly agree Agree Disagree Strongly disagree

6. I take a positive attitude toward myself.

Strongly agree Agree Disagree $\quad$ Strongly disagree

7. On the whole, I am satisfied with myself.

Strongly agree Agree Disagree Strongly disagree

8. I wish I could have more respect for myself.

Strongly agree Agree Disagree Strongly disagree

9. I certainly feel useless at times.

Strongly agree Agree Disagree Strongly disagree

10. At times I think I am no good at all.

Strongly agree Agree Disagree Strongly disagree 